\title{
Hippocampal Complex Contribution to Retention and Retrieval of Recent and Remote Episodic and Semantic Memories: Evidence from Behavioral and Neuroimaging Studies of Healthy and Brain- damaged People
}

\author{
Morris Moscovitch ${ }^{1,2}$, Robyn Westmacott ${ }^{3}$, Asaf Gilboa ${ }^{1}$, Donna Rose \\ Addis $^{1,3}$, R. Shayna Rosenbaum ${ }^{1,2}$, Indre Viskontas ${ }^{4}$, Sandra Priselac ${ }^{1,2}$, \\ Eva Svoboda ${ }^{1,2}$, Marilyne Ziegler ${ }^{1}$, Sandra Black ${ }^{1,5}$, Fuqiang Gao ${ }^{5}$, Cheryl \\ Grady $^{1,2}$, Morris Freedman ${ }^{1,2}$, Stefan Köhler ${ }^{6}$, Larry Leach ${ }^{2}$, Brian \\ Levine $^{1,2}$, Mary Pat McAndrews ${ }^{1,3}$, Lynn Nadel $^{7}$, Guy Proulx ${ }^{2}$, Brian \\ Richards ${ }^{2}$, Lee Ryan ${ }^{7}$, Kathryn Stokes ${ }^{2}$, and Gordon Winocur ${ }^{1,2,8}$ \\ ${ }^{1}$ University of Toronto, Canada \\ ${ }^{2}$ Baycrest Centre for Geriatric Care, Toronto, Canada \\ ${ }^{3}$ Toronto Western Hospital, Canada \\ ${ }^{4}$ University of California, Los Angeles, USA \\ ${ }^{5}$ Sunnybrook and Women's Hospital, Toronto, Canada \\ ${ }^{6}$ University of Western Ontario, Canada \\ ${ }^{7}$ University of Arizona, Tempe, USA \\ ${ }^{8}$ Trent University, Canada
}

Summary. For over a hundred years, it has been accepted that remote memories are less vulnerable to disruption than are recent memories. The standard consolidation model posits that the hippocampus and related structures are temporary memory structures, necessary for acquisition, retention, and retrieval of all explicit (declarative) memories until they are consolidated elsewhere in the brain. We review lesion and neuroimaging evidence showing that important distinctions exist among different types of explicit memory and the structures that mediate them. We argue that retention and retrieval of detailed, vivid autobiographical memories depend on the hippocampal system no matter how long ago they were acquired. Semantic memories, on the other hand, benefit from hippocampal contribution for some time before they can be retrieved independently of the hippocampus. Even semantic memories, however, can have episodic elements associated with them which continue to depend on the hippocampus. In short, the evidence reviewed suggests strongly that the function of the 
hippocampus (and possibly of related limbic structures) is to help encode, retain, and retrieve experiences, no matter how long ago the events comprising the experience occurred. We conclude that the evidence favors a multiple trace theory (MTT) of memory over the traditional model, and we indicate what future work is needed to resolve disputes.

Key words. Consolidation, Autobiographical Memory, Episodic Memory, Semantic Memory, Hippocampus, Medial Temporal Lobes

\section{Introduction}

How memories are formed, retained, and recovered is one of the central and enduring questions in psychology and cognitive and behavioural neuroscience. Writing in 1904, Burnham identified two processes that were implicated in consolidation, the formation of durable memories: (1) a physiological or biochemical process needed for formation and storage of a memory trace or engram, and (2) a psychological process needed to assimilate the newly-acquired memory into an already existing body of knowledge, and to allow it, in turn, to influence what will be learned subsequently. Elucidating these processes remains at the heart of research on memory and consolidation, and will be the focus of this chapter. In particular, we will examine two types of memory-episodic (autobiographical) and semantic - and investigate what studies of remote memory can tell us about the neural substrates mediating them, how they may be modified with time, and what implication that knowledge has for general psychological theories of memory.

Recent work has begun to clarify the nature of the separate yet interactive roles of the hippocampal complex and the neocortex in memory storage and retrieval. The hippocampal complex, located in the medial temporal lobe (MTL), includes the hippocampal formation, the peri-rhinal and entorhinal cortex, and the parahippocampal cortex, and is linked to other structures in the limbic system (see Figures $1 \& 2$ ). Most of the work in human and non-human species has focused on anterograde memory-the acquisition, storage, and retrieval of new or recently-acquired memory. These studies have been instrumental in calling attention to the role that different areas of neocortex and sub-regions of the MTL play in explicit and implicit memory, although the precise nature of those functions is still in dispute ( Burgess, Maguire, \& O'Keefe, 2002; Murray \& Bussey, 2001;

Murray \& Richmond, 2001; Squire \& Zola, 1998). Studies on the role of the MTL and neocortex in retrograde or remote memory are rarer, yet such 


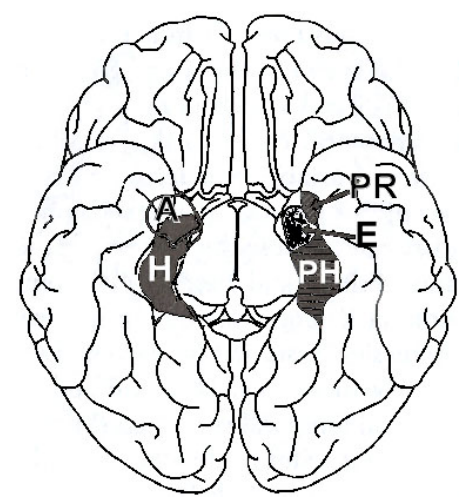

Fig. 1. Medial temporal lobe structures viewed from the underside of the brain. A: Amygdala; E: Entorhinal Cortex; H; Hippocampus; PH: parahippocampal cortex; PR: Perirhinal cortex.

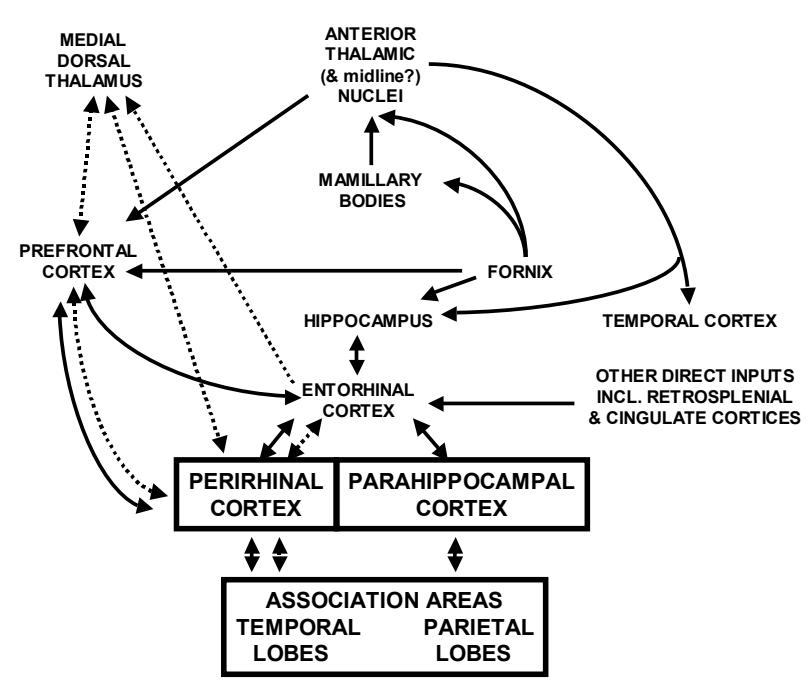

Fig. 2. The hippocampal-diencepahalic systems showing connections between medial temporal structures and diencepahlic (thalamic) nuclei and frontal lobes. Solid lines show the extended hippocampal system, presumed to mediate recollection, and dotted lines show the extended perirhinal system, presumed to mediate familiarity. (Modified from Aggleton \& Brown, 1999). 
studies are crucial for answering our central question: What is the role of the hippocampus and neocortex in consolidation, retention, and retrieval of memories acquired long ago?

The work reported in this chapter is a team effort. It began in 1996 while Morris Moscovitch was on sabbatical leave at the University of Arizona, where he was working with Lynn Nadel. Moscovitch was invited to present a talk on consolidation at a conference at Tel-Aviv University, and recruited Nadel as a co-author. Intending simply to update evidence favoring the standard view of memory consolidation, they reviewed the recent literature and realized that the data were much more troublesome to that view than they had anticipated. Instead of trying to fit the data to the standard model, they proposed a new one, to be described shortly (Nadel \& Moscovitch, 1997). Those ideas, however, would have had little credibility, and less currency, without the evidence gathered by a large team of investigators who at first were as skeptical of our ideas as were our critics. The research efforts of this large team nurtured the ideas that were hatched in Arizona and allowed them to take flight.

\section{A very brief history of the problem of remote memory and consolidation}

Over the last few years, a number of reviews have been written on consolidation (Dudai, 2004; Kandel, 2001; Moscovitch, 2001; McGaugh, 2000) so there is no need to repeat those reviews here. The term "consolidation" was introduced by Müller and Pilzecker (1900) to describe a timedependent process that was needed to assimilate an experience and store it permanently as a memory that was relatively immune to disruption. Although there was some sophisticated, prescient speculation about the processes involved in consolidation (Burnham, 1904), until 1950 little was known about the neural (but see Korsakoff, 1889) and biochemical substrates of memory or how they were implicated in consolidation.

The next half century saw a number of important developments but none was as momentous as Scoville and Milner's (1957) publication on the effects of excision of the anterior, medial temporal lobes (MTL) bilaterally to control intractable epilepsy in a single patient, H.M. ( for an MRI reconstruction of H.M.'s lesion, see Corkin, Amaral, Gonzalez, Johnson, \& Hyman, 1997). This publication was followed by a report of three additional cases with unilateral excisions with presumed damage to contralateral MTL structures (Penfield \& Milner, 1958). These cases focused atten- 
tion on the hippocampus and related structures in the MTL as being crucial for long-term memory. Although the surgery was effective in controlling H.M's epilepsy, one of its unanticipated consequences was that he developed a profound anterograde amnesia, while retaining normal intelligence, short-term memory, and perceptual and motor functions. The other patients suffered a similar fate. Remote memory loss was believed to be limited to about 3 years (Corkin, 1984; Milner, 1966; but see Corkin, 2002).

These observations were interpreted as showing that the medial temporal lobes and related diencepahlic structures were involved neither in processing short-term memories nor in storing remote memories. Instead, their function was to help encode and consolidate memories, and to store and retrieve those memories until consolidation was complete (Squire, 1992; Zola-Morgan \& Squire, 1990). Indeed, the standard model of consolidation was based on these initial observations and has been modified little since then (Milner, Squire, \& Kandel, 1998; Moscovitch, 2001).

\section{The standard model}

According to the standard model (Dudai, 2004; McGaugh, 2000; Squire \& Alvarez, 1995), memory consolidation begins when information, registered initially in neocortex, is bound into a memory trace by the MTL and related structures in the diencephalon. This initial binding into a memory trace involves short-term processes. The first of them may be completed within seconds, and involves transient molecular changes at the synapse. These, in turn, can give rise to a cascade of events, lasting minutes or at most days, which entail genetic transcription and protein formation that lead to long-lasting cellular changes, including the creation of new synapses ( Dudai, 2004; Kandel, 2001). These changes support the formation and maintenance of long-term memory. We refer to this process as rapid consolidation or cohesion (Moscovitch, 1995) or synaptic consolidation (Dudai, 2004) to contrast it with a process of prolonged consolidation or system consolidation (Dudai, 2004) which, according to the standard model, can last on the order of years or even decades.

During prolonged consolidation, it is assumed that the medial temporal lobes and related structures are needed for storage and recovery of the memory trace, but their contribution diminishes as prolonged consolidation proceeds, until the neocortex alone is capable of sustaining the permanent memory trace and mediating its retrieval (Markowitsch, 1995). Thus, the MTL and related structures are considered by the standard model to be temporary memory systems, needed to store and retrieve memories until 
prolonged or system consolidation is complete. The time it takes for consolidation to be complete is estimated by the temporal extent of retrograde amnesia following lesions of the MTL and diencephalon, other kinds of insults (concussions, closed head injuries, or electrical currents), or the administration of pharmacological agents which disrupt memory permanently.

The existence of rapid consolidation is not in dispute by proponents of the standard model nor by their adversaries. Much has been learned about its cellular and neurochemical (molecular) basis, which seem to be similar across species and across different memory systems in the same species (see Dudai, 2004; Kandel, 2001). We are, however, far from understanding memory at a systems level (but see Dudai, 2004; Frankland \& Bontempi, in press), a problem that is inextricably tied to ideas concerning prolonged consolidation, ideas which form the crux of the debate (Squire, Cohen, \& Nadel, 1984) and the focus of this chapter.

\section{Prolonged consolidation and memory systems}

By the 1960s, the outlines of the central debate concerning the validity of the standard model of consolidation were clearly crystallized in work with amnesic patients, reflecting the assumption that it was damage in the MTL and diencephalon that was primarily responsible for the amnesia (Warrington \& Sanders, 1971; Warrington \& Weiskrantz, 1970). Although the debate has many facets, in this chapter, the focus is only on one of them: What is the extent and duration of retrograde amnesia and, by implication, of consolidation, and how are they affected by lesion location and memory type?

\section{Types of memory}

One of the major contributions of memory researchers in the latter part of the $20^{\text {th }}$ century is the idea that memory is not unitary but consists of various types, each influenced by different variables, governed by different principles, possibly concerned with different materials, and each mediated by different neural structures and mechanisms that form distinguishable, and dissociable, systems (see Cermak, 1982; Moscovitch, 1992, 2001; Tulving \& Craik, 2000; Schacter \& Tulving, 1994). Although many different types of memory have been identified, including the broad classes of explicit (conscious) and implicit (unconscious) memory (Graf \& Schacter, 
1985; Moscovitch, Vriezen, \& Goshen-Gottstein, 1993), the two most relevant to the debate are episodic and semantic memory (Tulving, 1972, 1983), both of which can be considered explicit (Moscovitch, 1982, 1984; Schacter, 1987) or declarative (Squire, 1992).

Episodic memory refers to memory for particular, autobiographical episodes that have a distinct spatio-temporal context and involves a detailed re-experiencing of the initial event. Tulving (1985) refers to this reexperience as "mental time travel" which relies on autonoetic consciousness (consciousness with the self in it). In studies of anterograde memory, episodic memory is assessed by tests of recollection, which refers to representation of past experiences and includes not only the content of those experiences but also their spatial-temporal context. Building on Tulving's distinction, Moscovitch $(1995,2000)$ emphasized that episodic memory also includes the conscious experience accompanying the episode. Put succinctly, episodic memory refers to memory of the experience of the event, of which conscious awareness is a part.

Semantic memory, on the other hand, is knowledge that lacks a spatiotemporal context, such as knowledge of vocabulary and facts about the world (history, geography, people). Semantic memory even includes knowledge about ourselves (where we were born, where we lived, who our friends were, what schools we attended, what jobs we held), what some have called personal semantics (Cermak \& O'Connor, 1983; Kopelman, Wilson, \& Baddeley, 1989) to distinguish this aspect of memory from that for autobiographical episodes.

There is another type of memory that figures prominently in research, and that has elements of both semantic and episodic memory, and that is familiarity with a past event. Familiarity refers to recognition that an event had occurred to one personally but without the information needed to place it in an autobiographical context. For example, familiarity is the kind of memory that occurs when you encounter a person whom you recognize as familiar but you cannot place the individual or the encounter in a particular time or place. This memory shares attributes both with episodic memory, in that it is memory for a particular bit of information linked to an episode, and with semantic memory, in that it lacks a defining spatio-temporal context. As we shall see, these distinctions, which have gained in importance in studies of anterograde memory over the last decade, also have come to play an important role in studies of retrograde or remote memory.

Although different types of tests are used to assess episodic and semantic memory, proponents of the standard model consider them to be similar with respect to consolidation. According to these investigators, damage to the medial temporal lobes and diencephalon leads to a graded, temporallylimited retrograde amnesia for all types of declarative memory. Memories 
acquired most recently are most severely affected, with more remote memories being retained normally, having been fully consolidated before the neurological insult (see Bayley, Hopkins, \& Squire, 2003; Manns, Hopkins, \& Squire, 2003; Squire \& Alvarez, 1995, Reed \& Squire, 1998; Rempel-Clower, Zola, Squire, \& Amaral, 1996).).

\section{Critique of the Standard Model}

The standard model of consolidation had been challenged by Warrington and her colleagues who showed that retrograde amnesia can be severe and of long duration following medial temporal lesions. This finding led them to favor the view that amnesia results from a deficit in retrieval rather in consolidation (Warrington, 1996; Warrington \& Sanders, 1970; Warrington \& McCarthy, 1988). Kinsbourne and Wood (1975), on the basis of evidence they collected using Crovitz and Schiffman's (1974) cuing technique, argued that amnesia is a deficit only of episodic memory, and affects recent and remote memory equally. Although few endorsed their ideas at that time, Nadel and Moscovitch's (1997; Nadel et al., 2000) recent reviews sided more with their position than with the standard model. Nadel and Moscovitch noted a number of problems with the standard model, both with respect to the types of memories that are affected and with the duration and extent of retrograde amnesia.

Retrograde amnesia varied with memory type, decreasing in severity and extent from the autobiographical to the semantic. In people with large MTL (or diencepahlic) lesions, retrograde amnesia for details of autobiographical events can extend for decades, far longer than it would be biologically plausible for even prolonged consolidation to be completed, or even a lifetime. Retrograde amnesia for public events and personalities which, as we shall see is contaminated by autobiographical information, is less extensive and often is temporally graded; this is truer still of semantic memory that pertains to vocabulary, to facts about the world, and to personal semantics (see Fujii, Moscovitch, \& Nadel, 2000; Kapur, 1999, Kopelman \& Kapur, 2001; for extensive reviews of retrograde amnesia).

\section{The relevance of the neuroanatomical components of the medial temporal lobes and related structures}

It is a truism (or principle) in cognitive neuroscience that distinct psychological functions are associated with distinct neural substrates or processes. 
It is not surprising, therefore, that the new developments in our psychological understanding of memory were accompanied by comparable developments in our appreciation of the neuroanatomy of memory. Nadel and Moscovitch (1997, 1998; Nadel et al., 2000, 2003) noted that lesion size and location play a role in determining the nature, severity, and extent of retrograde amnesia. The initial studies on retrograde amnesia implicated the MTL and diencephalon. As we noted, however, these areas themselves are comprised of a number of separate, but related, structures (see Figure $1)$.

Following Scoville and Milner's (1957) report, attention shifted quickly from the medial temporal lobes to the hippocampal formation, and then to the hippocampus itself. More recently, however, investigators have begun to appreciate the importance of the other structures, the different functions each serves, as well as their relation to each other and to corresponding regions in the diencephalon ( see Aggleton \& Brown, 1999).

One system, consisting of the hippocampus and its connections to the mammillary bodies and anterior thalamic nuclei, is presumed to mediate recollection which relies on relational information, including the temporalspatial context of the memory (see Figure 2). Damage to this system causes deficits in spatial memory and in memory for complex relational information that typifies memory for autobiographical episodes, but spares recognition based only on familiarity (Aggleton et al., 2000; Holdstock et al., 2002a; Mayes et al., 2002, 2004; D. Moscovitch \& McAndrews, 2002; Yonelinas, 2002; Yonelinas et al., 2002). The other system, consisting of the peri-rhinal cortex and its connections to the dorsomedial nucleus of the thalamus, is necessary for item recognition based on familiarity judgments which do not require access to spatial-temporal context (see Figure 2). Damage to this system will impair recognition even of single items (Aggleton et al., 2000). The parahippocampal cortex seems to be necessary for forming memories of places (Epstein \& Kanwisher, 1998; Epstein, Harris, Stanley, \& Kanwisher, 1999; Epstein, Graham, \& Downing, 2003) or of associating objects with particular locations (Owen, Milner, Petrides, \& Evans, 1996a,b), and may provide the allocentric, spatial framework for recollection (Burgess, Becker, King, \& O'Keefe, 2001; Burgess, Maguire, \& O'Keefe, 2002; Nadel \& Moscovitch, 1997; O'Keefe \& Nadel, 1978; Rosenbaum et al., 2000).

Based on the functional and neuroanatomical evidence which they reviewed, Nadel and Moscovitch (1997, 1998; Moscovitch \& Nadel, 1998; Nadel et al., 2000) concluded, contrary to the traditional consolidation model, that the function of the medial temporal system is not temporallylimited but that it is needed to represent even old memories in rich detail, be they autobiographical or spatial, for as long as the memories exist. 
Nadel, Moscovitch and their colleagues (Fujii et al., 2000; Nadel \& Moscovitch, 1997; Nadel et al., 2000, 2003; Rosenbaum et al., 2000) noted that the extent and severity of retrograde amnesia depended on the size of the lesion - the larger the lesion, the greater the loss - with episodic, autobiographical memory being the most severely affected. They proposed that the entire medial temporal region, what has been called the hippocampal complex after its most prominent structure, is needed for storage and retrieval of episodic memories, however remote.

Given the multifaceted nature of autobiographical episodes, Nadel and Moscovitch $(1997,1998)$ suggested that each of the various regions of the medial temporal lobe may contribute its own information to the complete, detailed memory of an event, although they left the precise formulation vague. As we have learned more about the separate functions of medial temporal regions, it may make sense to consider the possibility that each of them is involved in retention and retrieval of those aspects of an event which they specifically process. Thus, for remote memory, as for anterograde memory, recollection of autobiographical episodes will always depend on the hippocampus. Recognition based on familiarity can survive hippocampal damage, but not damage to peri-rhinal cortex, whereas recognition of aspects of places will be impaired following parahippocampal lesions.

Neocortical structures, on the other hand, are sufficient to form domainspecific and semantic representations based on regularities extracted from repeated experiences with words, objects, people, and environments (Rosenbaum et al., in press). This applies even to autobiographical episodes that one recollects repeatedly, thereby creating a gist of each episode which lacks the details that makes rich re-experiencing possible. The MTL system may aid in the initial formation of these neocortical representations (Nadel \& Moscovitch, 1997), but, once formed, they can exist on their own. We return to this point later when we discuss semantic memory.

\section{Multiple Trace Theory}

Nadel and Moscovitch (1997) referred to their model as the Multiple Trace Theory (MTT) of memory (see Estes, 1964, for an earlier related psychological model). According to MTT, the hippocampal complex (and possibly diencephlon) rapidly and obligatorily encodes all information that is attended (consciously apprehended), and binds the neocortical (and other) neurons that represent that experience into a memory trace. This information is sparsely encoded in a distributed network of hippocampal complex 
neurons which act as pointers to, or index, the neurons that represent the attended information (Teyler \& DiScenna, 1986). A memory trace of an episode, therefore, consists of a bound ensemble of neocortical and hippocampal/medial temporal lobe (and possibly diencephalic) neurons which represent a memory of the consciously-experienced event. Formation and consolidation of these traces, or cohesion (Moscovitch, 1995), is relatively rapid, lasting on the order of seconds or at most days (rapid consolidation).

According to MTT, and in contrast to the standard consolidation model, there is no prolonged consolidation process that slowly strengthens the neocortical component of the memory trace so that with time it becomes independent of the hippocampal complex. Instead, each time an old memory is retrieved, a new hippocampally-mediated trace is created so that old memories are represented by more or stronger traces than are new ones, and therefore old memories are less susceptible to disruption from brain damage than are more recent ones. Because the memory trace for autobiographical episodes is distributed in the hippocampal complex, the extent and severity of retrograde amnesia, and perhaps the slope of the gradient, are related to the amount and location of damage to the extended hippocampal complex. This idea fits reasonably well with the available evidence (see Fujii et al., 2000; Nadel \& Moscovitch, 2001).

Whereas each autobiographical memory trace is unique, the creation of multiple, related traces facilitates the extraction of the neocorticallymediated information which is common among them, and which is shared with other episodes. This information is then integrated with pre-existing knowledge to form semantic memories that can exist independently of the hippocampal complex. Thus, facts about the world, people, public and even personal events (their gist, not contextually-rich information) that are acquired in the context of a specific episode can be separated from the episode and ultimately stored independently of it, although in some cases episodic information may be retained in parallel. This process of some memories becoming increasingly semantic may give an impression of prolonged consolidation, as we shall see later.

\section{Tests of MTT and the standard model: Autobiographical memory}

Recent research developments show, however, that autobiographical memory itself consists of multiple components, each likely mediated by different brain mechanisms (see Conway \& Playdell-Pierce, 2000; Conway \& Fthenaki, 2000; Conway et al., 2003; Ogden, 1993; Rubin \& Greenberg, 
1998; Greenberg \& Rubin, 2003, and references therein). Autobiographical memory appears to be organized hierarchically with life-time periods (e.g., high school, university, first jobs) at the top of the hierarchy, general event memories in the middle (going on vacation, visiting friends, family dinners), and unique, specific events which have detailed perceptual information at the bottom. Associated with each of these is semantic knowledge related to the event (e.g., with regard to vacation, general knowledge about the location being visited is incorporated into the memory). Finally, retrieval occurs within the "working self" (Conway \& Playdell-Pierce, 2000; Conway \& Fthenaki, 2000), a type of working memory that contains current conceptions of one's self and one's long-term and immediate goals that influence, direct, and monitor retrieval.

The aspect of autobiographical memory most relevant for our concerns is unique, specific events because it is these which correspond to autobiographical recollection, the feeling of traveling back in time and reexperiencing the event mentally. The greatest divergence between the two models concerns this aspect: MTT predicts that such event-specific memories always depend on the hippocampus, no matter how old they are, whereas the standard model predicts that only more recent memories are hippocampally-dependent.

To be sure, recalling event-specific information may also implicate other components of autobiographical memory and the structures that mediate them. For example, in recalling a specific event that occurred at one's home, knowledge of the house, the items in it, their location, and so on, forms the background against which the event-specific memory occurs. One of the tests that we have devised (Levine, Svoboda, Hay, Winocur, \& Moscovitch, 2002), The Autobiographical Interview, distinguishes between those elements that are specific to the event (internal details) and those which are shared with other events or are derived from general knowledge (external details).

Another way of distinguishing the experiential aspects of the event from those which are more generic is simply to count the number of details which an event conjures in memory (Moscovitch, Yaschyshyn, Ziegler, \& Nadel, 1999) or rate the memory along dimensions such as vividness (Addis, Moscovitch, Crawley, \& McAndrews, 2004a; Gilboa, Winocur, Grady, Hevenor, \& Moscovitch, 2004). According to MTT, only those autobiographical memories high in internal details and vividness depend on the hippocampus, no matter how old they are. It remains to be seen whether generic memories, or other aspects of specific event memoriessuch as their semantic component or familiarity - also continue to depend on the hippocampus (see Addis, McIntosh, Moscovitch, Crawley, \& 
McAndrews, 2004b; Graham, Lee, Brett, \& Patterson, 2003, for relevant neuroimaging studies).

Although this chapter emphasizes the medial temporal lobe, and in particular the hippocampus, one should not lose sight of the fact that retrieving autobiographical memories requires the interaction of the medial temporal lobes with other neocortical and subcortical structures. We are mindful of the contribution of these other structures, but will refer to them only occasionally here (for more information, see Addis et al., 2004a, b; Conway \& Pleydell-Pierce, 2000; Conway \& Fthenaki, 2000; Gilboa, 2004; Gilboa et al., 2004; Graham et al., 2003; Maguire, Vargha-Khadem, \& Mishkin, 2001; Maguire \& Frith, 2003; Murre, Graham, \& Hodges, 2001; Piefke, Weiss, Zilles, Markowitsch, \& Fink, 2003; Ryan et al., 2001).

The studies we present in the following sections are our own, and are not meant to provide a comprehensive review of the area. We will refer to other studies as needed, and will try to note discrepancies with other studies when they bear on the main questions being addressed.

\section{Neuroimaging}

According to the standard model, activation of the hippocampal complex should be greater for recent than for remote memories, whereas the reverse should be the case for the neocortex. MTT, however, predicts that the hippocampal complex will be activated equally by retrieval of recent and remote autobiographical memories, as long as they are vivid or detailed. Using cues (Ryan et al., 2001) or statements (Maguire, 2001; Maguire et al., 2001, 2003) derived from pre-scan interviews, and event-related functional magnetic resonance imaging (efMRI) designs, investigators have found greater bilateral hippocampal activation associated with re-experiencing of particular autobiographical events, or mostly left-sided activation while making recognition judgments about statements referring to autobiographical events in comparison to control conditions that included general personal events or public events. Most importantly, hippocampal activation was equivalent for recent and remote memories, thereby favoring MTT over the standard model. Piolino, Giffard-Quillon, Desgranges, Che'telat, Baron, \& Eustache (2004) reported similar findings and conclusions using positron emission tomography (PET).

A possible confound in these studies concerns item selection. Because participants selected the memories used in the experiment, either right before scanning or even weeks earlier, it is difficult to know whether they re- 
trieved truly remote memories in the scanner, or only refreshed those memories which were recovered more recently during the selection process. Ryan et al. (2001) controlled for this possible confound by scanning three additional participants whose autobiographical events were selected by a close relative or friend, and Maguire et al.(2001) controlled for it by testing the developmental hippocampal amnesic, Jon, for the few events he could recollect from his remote past, even though he had no memory for the pre-scan interview. In both cases, greater hippocampal activation - that did not vary with time - was found for autobiographical than for other events.

Another possible confound is that hippocampal activation accompanies re-encoding of memories as they are retrieved in the scanner, rather than being associated with the initial retrieval itself. Sensitive to this criticism, Gilboa et al. (2004) addressed it in their study. They had a person close to the participant select family photos which the participant had not viewed recently and which were shown only in the scanner. The photos were from five time periods dating from early childhood (at least 20 years ago) to the last six months. To control for the effect of re-encoding, the participant also was presented with photos from a stranger's family album which were matched as much as possible in content to the participant's own photos.

On viewing "self" photos in the scanner, the participant had to reexperience the depicted event in as much detail as possible; in viewing the "other" photo, the participant had to imagine in equivalent detail a scenario concerning the event depicted in the unfamiliar photo. If re-encoding were a factor, no difference in hippocampal activation should be observed between the "self" and "other" conditions. Gilboa et al. (2004) found that activation was greater for old, "self" memories than for novel, imagined "other" material in a number of regions, including the left hippocampal complex (see also Addis et al., 2004a; Maguire et al., 2001), thereby arguing against the re-encoding interpretation.

Of equal interest was the finding, consistent with MTT but not with the standard model, that left hippocampal activation was related not to the age of the memory, but rather to its richness, as determined by post-scan vividness ratings for all of the memories and description for a subset of them from each time period (see Figure 3). Because Gilboa et al. (2004) found that, on average, recent memories are more vivid and detailed than remote memories, it is likely that these variables, rather than age, account for the temporally-graded hippocampal activation reported in other studies (Eustache et al., 2003; Maguire \& Frith, 2003; Niki \& Luo, 2002; Piefke et al., 2003). 


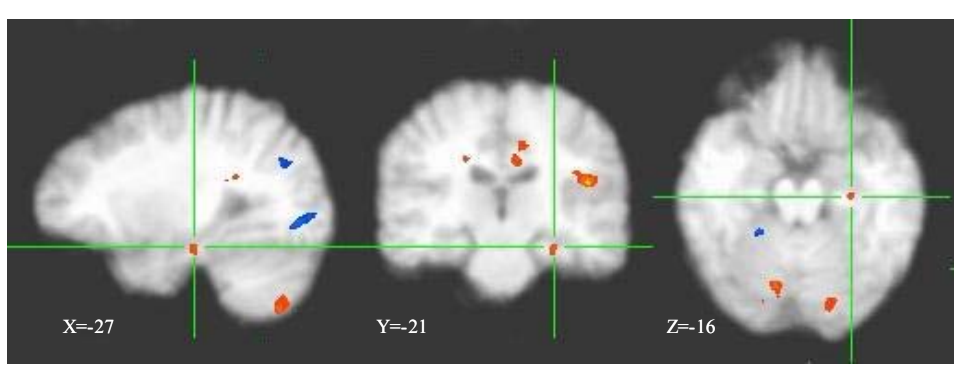

Fig. 3. Activation from vividly (red) versus non-vividly (blue) recalled events. The cross hairs on the images are centered at activations within the spherical search regions of the hippocampus which have the following Talairach and Tournoux (1988) co-ordinates: Reading from left to right, $x=-27, y=-21, z=-16$ ). Radiological co-ordinates are used so that left-right is reversed. (From Gilboa et al., 2004).

This interpretation was confirmed in a parallel efMRI study by Addis et al. (2004b) designed to determine whether recency or recollective qualities, such as detail, emotionality, and personal significance, modulate hippocampal activity during retrieval of autobiographical memories of unique or repeated events. During scanning, participants retrieved temporally specific autobiographical memories and general, repeated autobiographical memories, and rated each for level of detail, emotionality, or personal significance. Addis et al. found that medial temporal activation during the retrieval of either specific or repeated autobiographical memories varied with the level of detail, personal significance, and emotionality. Recency independently modulated hippocampal activity, but its effects were reduced or eliminated when the other factors were included as a covariates. Conversely, robust modulation of hippocampal activation was observed for the three qualities even when recency was included as a covariate. Consistent with MTT, the results suggest that recollective qualities, not recency, are the important predictors of hippocampal engagement during retrieval of autobiographical memories.

Gilboa et al. (2004) also found that foci of activation in the hippocampus were distributed differently for recent and remote memories, with the former clustered in the anterior region of the hippocampus and the latter distributed along its rostro-caudal axis (see Figure 4). It is not yet clear why this pattern should occur. If each retrieval leads to the formation of new traces within the MTL, as MTT predicts, then remote memories should be more widely distributed than recent memories in MTL, and may survive minimal damage to the MTL. 


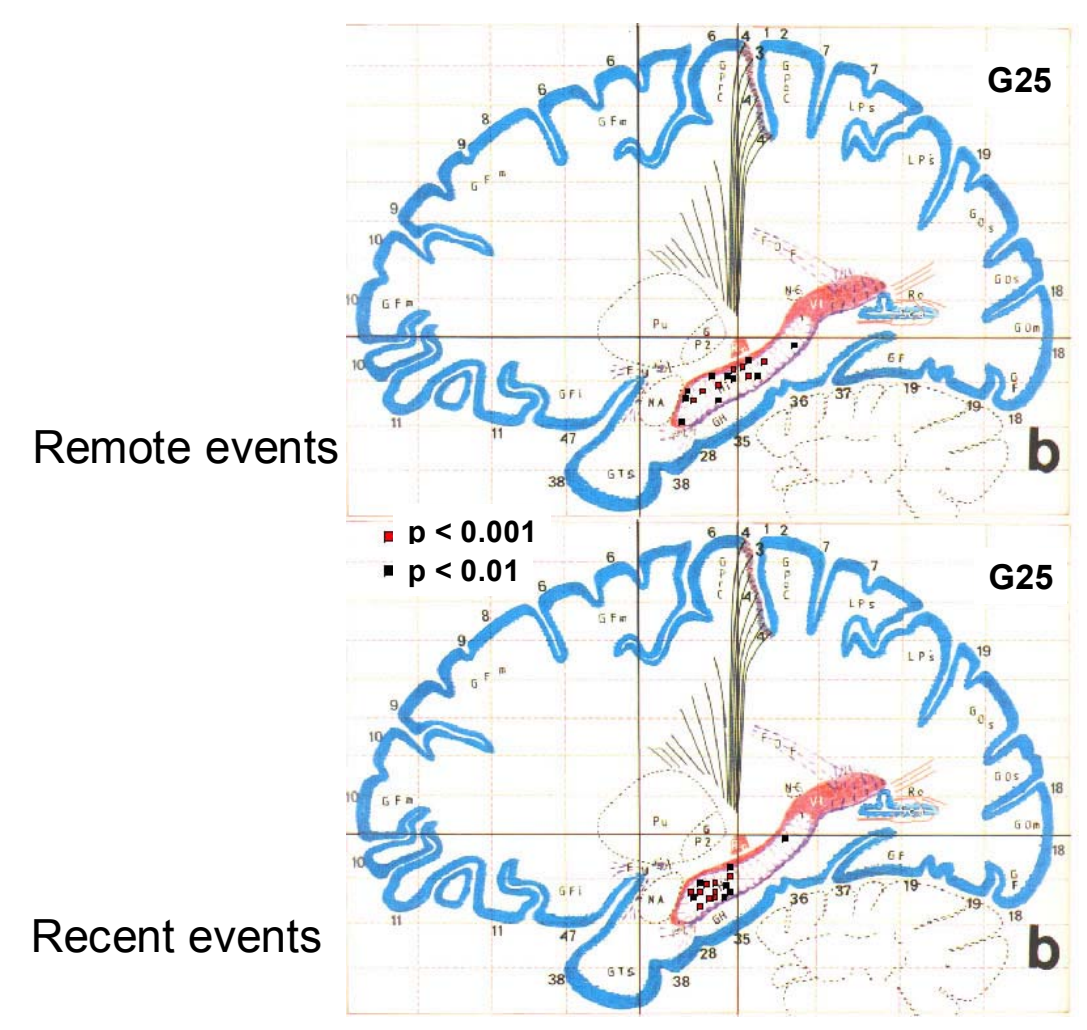

Fig. 4. Schematic renderings of remote and recent activations. Each point corresponds to a statistically significant activation from within the left hippocampus in either remote (top; $n=18$ ) or recent (bottom; $n=16$ ) conditions. Red and black squares represent activations at a significance level of $P<0.001$ and $P<0.01$ uncorrected, respectively. Activations are shown on a single sagittal plane taken from the Talairach and Tournoux (1988) atlas (25 mm lateral to the midline). Overlapping activations were offset slightly in the recent condition. Differences in the lateral displacement of the activations from the midline (along the $x$-axis of the Talairach atlas) are not represented in the figure. The lateral and vertical dimensions did not show any obvious systematic variability and therefore are not considered as a part of the overall pattern of interest. (From Gilboa et al., 2004). 
Other possible interpretations of this pattern of activation are that remote memories, particularly those dating to childhood and adolescence, may be encoded differently from more recent, adult memories, or that recent memories may retain their emotional strength more than remote ones. With respect to the latter possibility, Dolcos et al. (2002) reported that emotional memories activated the anterior hippocampus more than nonemotional ones, although in their study emotionality interacted with recollection, and all their memories were recent by our standards.

Summary. The neuroimaging studies that we have conducted support MTT's predictions that the hippocampal complex is needed for retention and retrieval of rich autobiographical memories no matter how old those memories are (see also Conway et al., 1999, and the review by Maguire, 2001). Our findings also help explain why recent autobiographical memories sometimes lead to greater hippocampal activation than do remote memories: Recent memories tend to be more vivid and experientially richer than remote ones. Once these qualities of memory are controlled or factored out, recency no longer is a modulating influence on hippocampal activation. The foci of activation for recent and remote memories were distributed differently in the hippocampus, the former clustering in the anterior portion, and the latter distributed along the rostrocaudal axis. Together, these studies indicate that it is the richness of the memory or the reexperience, rather than its age, that determines the extent of hippocampal involvement. This pattern is consistent with MTT, but contrary to the standard consolidation model.

\section{Lesion studies}

Despite the confirmatory evidence from neuroimaging studies, these results are fundamentally correlational: They indicate that the hippocampus is implicated in retrieving remote autobiographical memories, not that it is needed to do so (Shimamura, 2002). Only evidence from lesion studies can address that question conclusively. If the hippocampal complex is needed for retrieval of remote autobiographical memories, then damage to it should lead to remote memory deficits.

The evidence in the literature is mixed on this point. In reviewing the literature until 1998 on damage restricted to the medial temporal lobe, Fujii et al. (2000) noted that as the damage extends from the hippocampus proper to the adjacent medial temporal lobe regions, so does the extent of retrograde amnesia from a few years to a lifetime, if the entire complex is implicated. In the few cases in which damage was confined to the hippo- 
campus proper, retrograde memory loss was limited to just a few years. Some recent studies, however, suggest that severe and extensive retrograde amnesia for autobiographical events can occur even with damage confined to the hippocampus (Cipilotti et al., 2001, and discussion in Nadel \& Moscovitch, 2001). As well, H.M.'s retrograde amnesia which was reported to last only for three years (Scoville \& Milner, 1957), has been extended to 11 years (Corkin, 1984), and even longer ( Corkin, 2002) for his autobiographical memory.

A possible reason for the discrepancy among the studies is that the measures used to assess remote autobiographical memory were not sensitive enough to capture its richness, or to distinguish the specific, episodic component from the more generic or semantic one. Typically, autobiographical memory is scored on a three-point scale, with the maximum number of points awarded if information about the temporal-spatial context is supplied along with some details (Crovitz \& Schiffman, 1974; Kopelman et al, 1989). Such a system, however, would not distinguish between a report that contains just enough information to get a maximal score and one that supplies far more details. Scoring memories according to the total number of details that are supplied, much as one would score the logical stories on Wechsler Memory Scale for anterograde memory, would provide a more accurate measure of how well remote memory is preserved. By adopting this new scoring technique, we showed a remote memory deficit for all time periods except early childhood, where it was absent not because memory in amnesic patients was good, but because memory in normal people was also impoverished (Moscovitch et al., 1999; Nadel et al., 2000).

As informative as that study was, leading to development of a new, reliable method of assessing remote memory (Levine et al., 2002), the amnesic patients who participated in it were a heterogeneous group, none of whom had damage confined to the hippocampal complex. To determine whether similar extensive memory loss could be observed in people with medial temporal lobe damage, we tested people with unilateral temporal lobe epilepsy either before or after anterior, medial temporal lobectomy (Viskontas, McAndrews, \& Moscovitch, 2000). Even though we used a standard test of autobiographical memory (The AMI by Kopelman et al., 1989), we found a retrograde memory loss dating back to early childhood, with no temporal gradient, even in individuals with late onset (after age 16) seizures (See Figures 5a,b). In fact, there is a suggestion that the deficit was more severe in the late onset cases, paralleling Seidenberg et al.'s (1997) finding on anterograde memory loss. Personal semantic memory, however, was unaffected at all time periods tested (see Figure $5 \mathrm{c}$ ). 


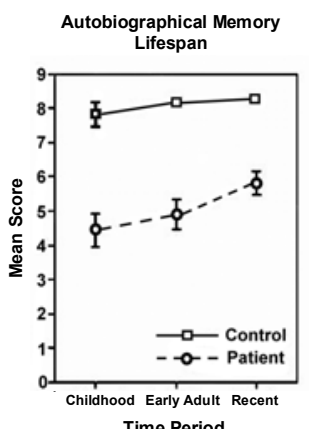

Time Period

a

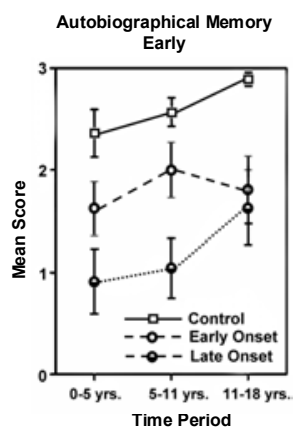

b

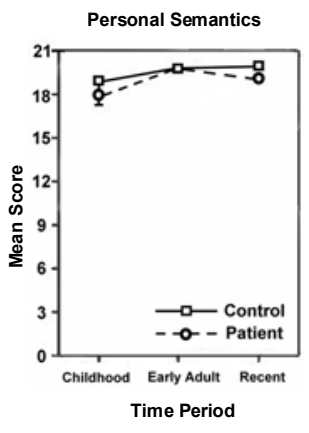

c

Fig. 5. Left panel: Autobiographical episodic memory performance. Mean scores on episodic components of the Autobiographical Memory Interview (AMI; Kopelman et al., 1989) for control $(n=22)$ and patient $(n=25)$ groups. The maximal score is 9 per time period. Vertical lines depict standard errors of the means. Middle panel: Autobiographical episodic memory performance during earliest time periods. Mean scores on episodic components of AMI for control $(n=22)$, late seizure onset $(n=11)$, and early seizure onset $(n=8)$. Late seizure onset describes patients who reported first seizures after age 18, early seizure onset describes patients who reported first seizures before age 5. The maximum score is 3 per time period. Right panel: Personal semantic memory performance. Mean scores on semantic components of AMI for control $(n=22)$ and patient $(n=25)$ groups. The maximum score is 21 per time period. Vertical lines depict standard errors of the means. (From Viskontas et al., 2001).

These findings do not imply that remote autobiographical memories are lost; rather, they indicate that remote memories are impoverished. Even severely amnesic people may retain the gist of particular events without the rich detail that allows them to be re-experienced vividly. The convergence of amnesic and normal memory at remote time periods that sometimes is observed, and that can give the impression of a temporal gradient, likely occurs because many remote memories, even of neurologicallyintact people, are impoverished, less experiential and more semantic (Cermak \& O'Connor, 1984) compared to their recent memories (see Gilboa et al., 2004), and not because remote memories are preserved in amnesia.

Proponents of the standard model argue, however, that severe, and temporally extensive, retrograde amnesia is observed for autobiographical events only if the lesion encroaches on the lateral temporal cortex, not if it is confined to the medial temporal lobe. Thus, working with people with such circumscribed lesions, Bayley, Hopkins, and Squire (2003) reported 
that autobiographical memories of the first third of their patients' lives (dating back 20-40 years) were normal, even though they used Levine et al.'s (2002) more sensitive scoring technique. The methods used for eliciting the memories, however, were different from those used by Moscovitch et al. (1999) and Levine et al. (2002), and judging from the data, they were not as effective. Indeed, whereas the number of details, both event-specific (internal) and generic (external), produced by control subjects in Bayley et al.'s study averaged only 18 per memory, those in Levine et al.'s and Moscovitch et al.'s study averaged 100. Indeed, their controls produced far fewer details than many of our amnesics, some of whose lesions were substantially larger than the lesions of Bayley et al.'s patients.

It is very likely that the memories sampled by Bayley et al. (2003) were not what we have called vivid, or experientially rich, memories, and would likely not require much hippocampal participation to retain or retrieve them. The source of the difference between our findings and theirs more likely lies in the kind of memories sampled (vivid vs impoverished) rather than only in differences of lesion location and extent in the two populations. Furthermore, we note that the pre-operative temporal-lobe epilepsy patients studied by Viskontas et al (2000) were equally impaired in retrograde memory as those who had undergone temporal-lobe resection, which clearly involved a considerable extent of removal of temporal neocortex.

Even MTT, however, posits that the amount of MTL damage should correlate with the severity and extent of retrograde amnesia for autobiographical events. Using MRI volumetry in a group of mild to moderate AD patients, Gilboa et al. (submitted b) found a strong correlation between extent of remaining tissue in bilateral MTL and anterior lateral temporal cortex on the one hand, and retrograde autobiographical memory loss, on the other, although the pattern was not sensitive to the age of the memory tested. No such correlation, however, was evident in a study of patients with focal lesions (Kopelman et al., 2003). Exactly what accounts for this discrepancy remains to be determined.

Likewise, there is disagreement concerning the effects of semantic dementia (SD) on autobiographical memory loss (see Graham \& Hodges, 1997; Graham, Patterson, \& Hodges, 1999; Murre et al., 2001). Neural degeneration associated with SD affects primarily the anterior and lateral temporal cortex, typically on the left, leaving the MTL relatively spared (Mummery, Patterson, Price, Ashburner, Frackowiak, \& Hodges, 2000). If remote autobiographical memories are represented in neocortex, as the standard model predicts, then patients with SD should show impaired memory for remote events but preserved memories for recent ones, a pattern opposite to that which the consolidation model predicts for amnesia. This is exactly what Graham et al. (1997) reported. 
Westmacott, Leach, Freedman, and Moscovitch (2001), however, argued that this pattern is observed only because patients with SD do not have the verbal means necessary to comprehend and express themselves adequately. Given non-verbal cues, such as family photos of particular events, and the opportunity to communicate by gestures, intonation, and so on, the SD patient tested showed that remote autobiographical memory was relatively preserved, a finding corroborated by Moss et al. (2003), Ivaniou, Cooper, Shanks, and Venneri (2003), and Piolino et al. (2003). Graham et al.'s patients, however, continued to be impaired in retrieving all memories except those from the last two years, even when they were tested using Westmacott et al.'s methods (Nestor, Graham, Bozeat, Simons, \& Hodges, 2002).

The source of the discrepancy among these studies remains unknown. A likely possibility is that the extent and locus of degeneration differs among patients, but whether the differences lie in MTL, anterior and lateral temporal lobes, or even prefrontal cortex (PFC), has yet to be determined.

Summary. The results of lesion studies are more variable than those from neuroimaging studies, because the methods used differ across studies, as do the size and location of lesions and degeneration. On balance, however, the results favor the MTT: Damage to the hippocampal complex leads to temporally extensive loss of detailed autobiographical memories. These lesion findings indicate not only that the hippocampus is implicated in the retention and retrieval of these memories, as neuroimaging studies had already shown, but that it is essential for these functions. Some questions remain to be resolved: Is the severity and temporal extent of the autobiographical memory loss related to the size of MTL lesions or degeneration, and does degeneration of anterior and lateral temporal cortex in SD spare recent, but not remote, memories?

\section{Parallels between anterograde and retrograde memory: A common mechanism?}

The evidence from studies of retrograde amnesia - that the MTL, and particularly the hippocampus, is needed for retention and retrieval of rich autobiographical memories, or re-experiencing of past events-dovetails with emerging evidence from studies of anterograde memory. As we noted earlier (p. 4), Tulving (1985) distinguished between two aspects of recognition, and of memory in general: recollection and familiarity. Aggleton and Brown (1999), working in a somewhat different tradition, had already distinguished between the extended hippocampal system, which is needed 
for recall, and the peri-rhinal system, which suffices for recognition (see above, p. 6). Investigators were quick to see the parallels between Aggleton and Brown's proposal and Tulving's distinction between recollection and familiarity (Yonelinas, 2002).

A number of studies showed that recollection was disproportionately impaired following lesions that included the hippocampus, whereas familiarity was relatively spared (Holdstock et al., 2002a, b; Mayes et al., 2003, 2004; D. Moscovitch \& McAndrews, 2000; Yonelinas et al., 2002). Concurrently, neuroimaging studies appeared which showed that the hippocampus was activated preferentially during recognition of items that were recollected as compared to those which were only considered familiar (Dolcos et al., 2002; Eldridge, Knowlton, Furmanski, Bookheimer, \& Engel, 2000; Davachi, Mitchell, \& Wagner, 2003). Our own preliminary findings (Caza et al. , 2004) have shown that even for recognition of newly learned associations, those which are accompanied by recollection show the greatest hippocampal activation. This finding emphasizes that recollective experience, rather than simply the retention and recovery of newlyformed associations, is the salient factor in hippocampal memory processes.

These studies on recollection and familiarity in anterograde memory add the virtue of parsimony to the MTT: The same processes which implicate the hippocampus in anterograde memory also implicate it in remote memory. If we accept this evidence, there is neither need nor reason to believe that the functions and representations that depend on the hippocampus during recent memory, stop depending on it for remote memory. According to this belief, which forms the basic tenet of the standard model, other structures, which did not possess the capability initially to support recollection, would assume that function once consolidation is complete. Even if this were biologically plausible, it adds complexity where complexity is not needed.

It is important in all of these discussions to emphasize that when we say that representations depend on the hippocampus or are mediated by it, we do not mean that they reside there, any more than that a melody resides in the keys of a piano (Wechsler, 1963). As argued by us (Nadel \& Moscovitch, 1997, 1998) and others (P. Milner, 1989; Teyler \& DiScenna, 1986), the hippocampus contains sparse codes that bind and orchestrate information that is distributed in many brain regions into a multifaceted memory of a past experience. Without hippocampal involvement, that information cannot be unraveled in a way that would capture the experience. In short, the hippocampus allows re-experiencing to occur. To push the musical analogy further, the hippocampus provides the score that is crucial for orchestrating the music which emerges from the neocortical players. 


\section{Semantic memory for facts, events, people, and words}

Damage to extra-hippocampal structures in the medial temporal lobes can lead to loss of remote memories for facts, events, and people, with the latter being particularly associated with damage to the anterior temporal pole (Tranel, Damasio \& Damasio, 1997). Loss of semantic memory, including loss of vocabulary and conceptual knowledge, is associated with damage to posterior neocortical structures, particularly the lateral aspects of the temporal lobe.

It is not known which areas are implicated in the loss of personal semantics. Semantic loss is evident in many patients with dementia and neocortical degeneration, including people with semantic dementia whose MTL is relatively spared (Graham \& Hodges, 1997; Snowden, Griffiths, \& Neary, 1994, 1996), as is their autobiographical memory (Kitchener and Hodges, 1999). As noted earlier, although there is controversy as to whether people with SD have a memory loss for remote, autobiographical events, there is agreement that semantic memory is impaired except for information acquired or used most recently.

With respect to amnesia associated with MTL damage, investigators of all theoretical persuasions agree that loss of pre-morbid semantic memory following MTL damage is temporally-limited, with remote memories being more resilient, a pattern opposite to that observed in SD (Fujii et al., 2000; Manns, Hopkins, \& Squire, 2003; Murre et al., 2001). This stands in stark contrast to the extensive retrograde loss of autobiographical memory in people with MTL lesions.

These differences between SD and MTL amnesia are illustrated in Figures 6 and 7 where we can compare the performance of K.C., a person with large bilateral, hippocampal lesions (Figure 6 ), to that of E.N., a person with semantic dementia (Figure 7) (Wetmacott et al, 2001; Westmacott and Moscovitch, 2002). Despite having widespread damage in other cortical and subcortical areas (see Rosenbaum et al., 2000, in press), K.C.'s intelligence is in the normal range as is his knowledge of words and people for all time periods except for the 5-10 year period immediately preceding his accident, and at all times subsequent to it. By comparison, E.N.'s recent memory for words and names is better than her remote memory for them.

We interpret the performance of E.N. as showing that the medial temporal lobes, which are relatively preserved in her, can mediate retrieval of semantic memory because they still retain some autobiographical significance, mediated by the hippocampus, and it is by virtue of this experience- 

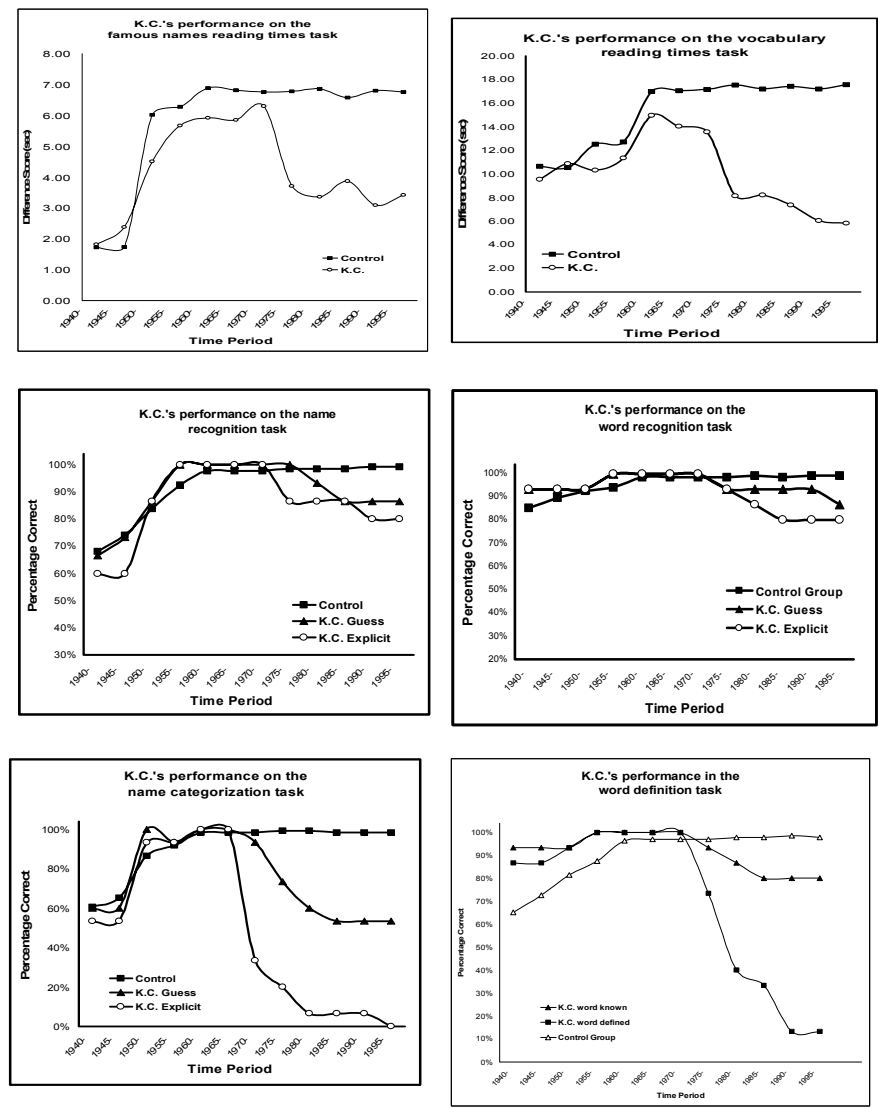

Fig. 6. Performance of healthy controls and K.C., an amnesic person with bilateral hippocampal lesions, on tests of semantic memory. Left panel, Famous Names: top: Difference in reading time (sec/list of 15 words) between unfamiliar names and names of people who became famous in each of five year periods between 1940 and 1995. The greater the difference, the more familiar the name is to the person being tested. K.C. sustained his injury in 1981. Middle: Percent correct responses in a three-alternative forced-choice in which participants selected the name belonging to a famous person. Confident responses are compared to guesses. Bottom: Percent correct responses in a three-alternative forced choice in which participants select the appropriate category (e.g., politician, actor, athlete). Confident responses are compared to guesses. Right panel, Words: The measures are the same as in the left panel, except that participants now are tested on words that entered the language in each of five year periods between 1940 and 1995. (Modified from Westmacott \& Moscovitch, 2001, 2002; Wesmacott et al., 2002). 

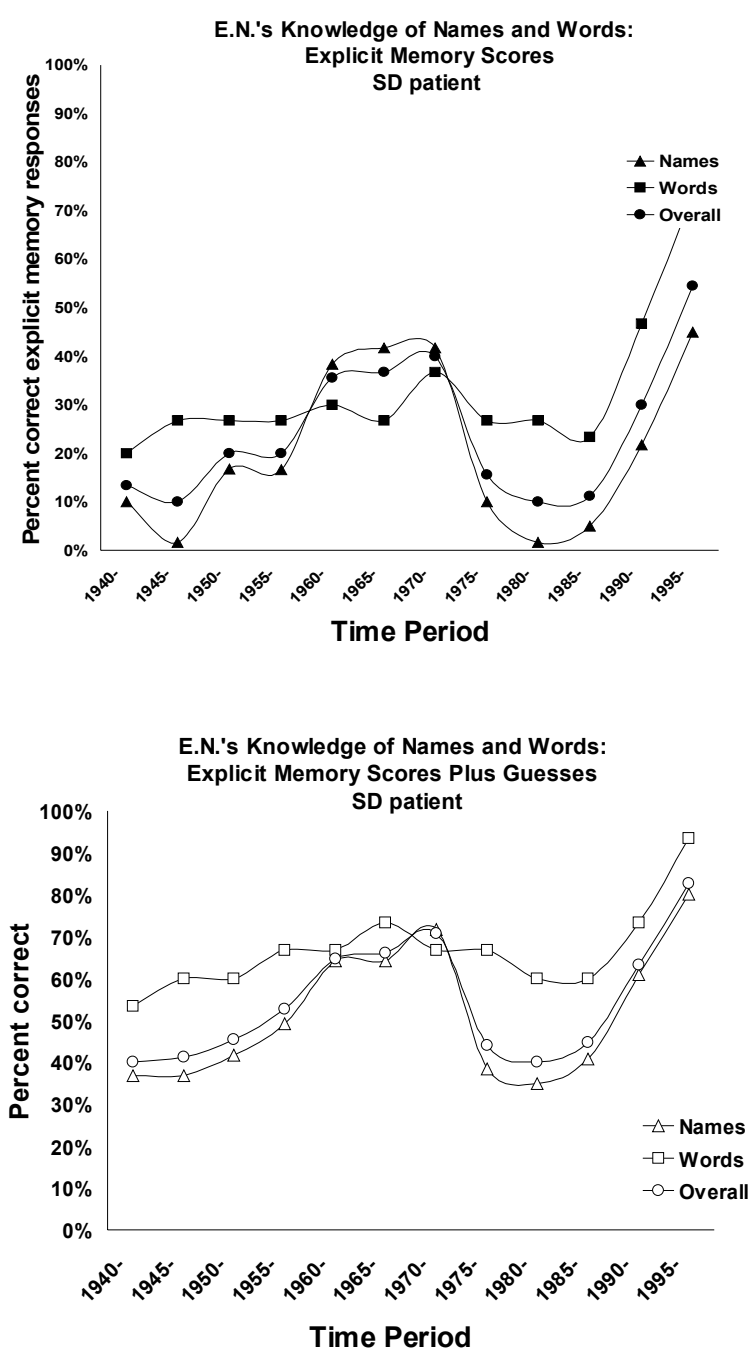

Fig. 7. Performance of E.N., a person diagnosed with semantic dementia, on tests of semantic memory. Names and Words: Percent correct responses in a threealternative forced-choice in which participants selected the name belonging to a famous person from two non-famous names, and the real word from two nonwords. Top panel shows only confident responses. Bottom panel combines the score from confident responses and guesses. Healthy controls scored over $90 \%$ correct with no change across time. (From Westmacott \& Moscovitch, 2002). 
based trace that the "semantic" memory is recovered. In people with degeneration of the MTL and lateral and anterior temporal cortex, as occurs in Alzheimer's Disease (AD), the losses resulting from damage to both structures combine, and we observe an extended and graded retrograde amnesia for names and words that seems to be related to the severity of the disorder (Westmacott \& Moscovitch, 2003, and Figure 8 a). As the disease progresses, the gradient extends further back in time (Figure $8 \mathrm{~b}$ ). The implication of these findings, and of similar ones reported by Piolini et al. (2003), is that the most remote semantic memories are represented more strongly in the neocortex, or distributed more widely, so that they are less vulnerable than more recently-acquired memories to neuronal degeneration or loss.

Recent evidence from studies on the acquisition of semantic memory in children whose hippocampus was damaged at birth, or shortly thereafter (Vargha-Khadem et al., 1997, Gadian, Aicardi, Watkins, Porter, Mishkin, Vargha-Khadem, 2000)., and in adults with hippocampal lesions (Kitchener, Hodges, \& McCarthy, 1998; O’Kane, Kensinger, \& Corkin, 2004; Skotko et al., in press; Van der Linden, Cornil, Meulemans, Ivanoiu, Salmon, \& Coyette, 2001; Westmacott \& Moscovitch, 2001), suggests that acquisition of semantic memory is not dependent on the MTL, but certainly benefits from it (but see Kitchener \& Squire, 2000). Neuroimaging studies support these observations. In a test of memory for faces of famous people, which can be considered a test of semantic memory, Haist, Bowden Gore, and Mao (2000) found greater activation in the entorhinal cortex for faces of people who became famous in the most recent decade than in all other decades. Similar findings were reported by Leveroni et al. (2000). This 10-year gradient is consistent with that reported in lesions studies (Manns et al., 2003; Westmacott et al., 2001,2002).

Taken together, the results from the lesion and neuroimaging studies speak to a fundamental distinction between remote memory for episodic and semantic information. Whereas detailed memory for autobiographical episodes is dependent on the medial temporal lobes for as long as the memory exists, memory for semantic information benefits from the MTL (hippocampus and peri-hippocampal cortex) for only a limited time, and can be acquired, slowly and with difficulty, without it. Observations regarding the fate of remote semantic memory, and the acquisition of new semantic memory, following medial temporal and neocortical lesions and degeneration are consistent both with the traditional model and MTT, although the mechanisms used to explain the findings differ. We discuss these alternatives next. 


\section{Longitudinal Performance of Patient C.T.} Explicit Word Recognition

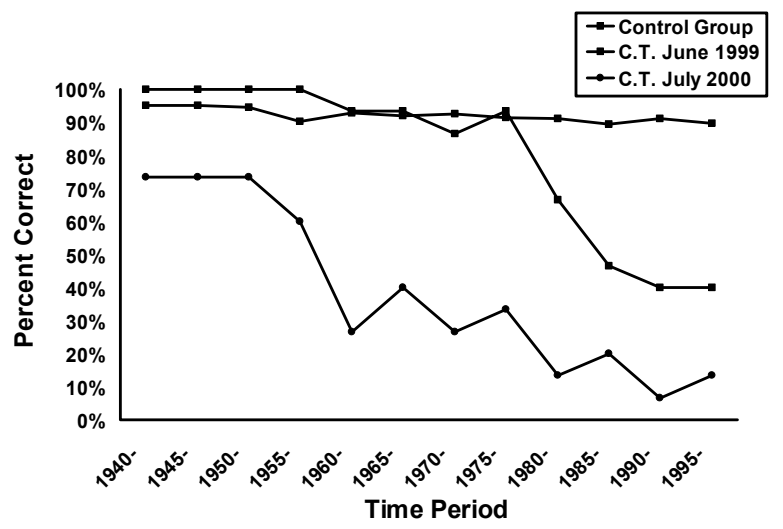

Longitudinal Performance of Patient C.T. Explicit Word Recognition

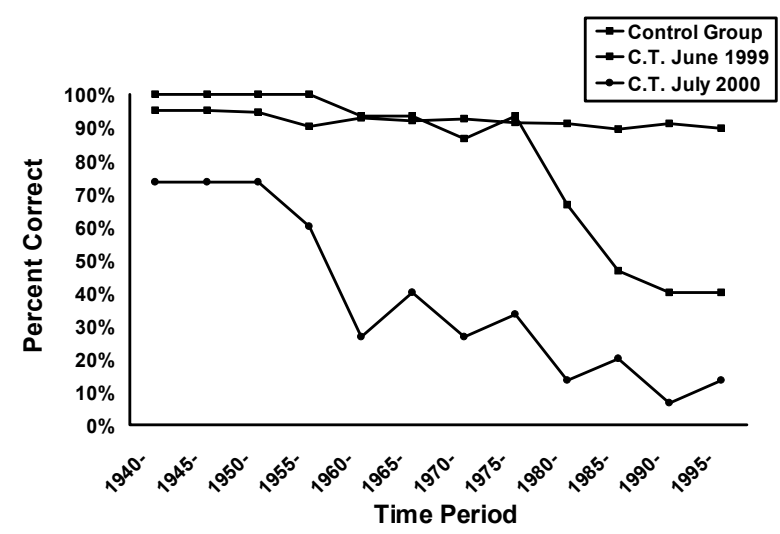

Fig. 8. Performance of C.T., a person diagnosed with Alzheimer's Disease in the mid-1990s, on tests of semantic memory. Percent correct responses in a three-alternative forced-choice in which participants selected the name belonging to a famous person from two non-famous names (top panel), and the real word from two non-words (bottom panel). The person was tested at two intervals, a year apart, to chart the decline. Only confident responses are displayed. (From Westmacott, Freedman, et al., 2004). 


\section{Prolonged consolidation for semantic memory: Two alternatives}

MTT provides the following account of the interaction of episodic with semantic memory. Whereas each autobiographical memory trace is unique, the creation of multiple, related traces facilitates the extraction of the neocortically-mediated information which is common among them, and which is shared with other episodes. This information is then integrated with preexisting knowledge to form semantic memories that are represented permanently in neocortical structures specialized in processing the information and capable of being modified while doing so. Eventually, those memories can be retained and retrieved independently of the hippocampal complex. This process of memories becoming increasingly semantic or generic, was first proposed by Cermak and O'Connor (1984; Cermak, 1989) to explain the preserved memories, both personal and public, of amnesic people.

According to the standard model, however, the memory that is held temporarily in the medial temporal lobes is identical to the memory that later is stored permanently in neo-cortex. Indeed, many believe that prolonged consolidation effects a transfer of the same memory from one location to another by strengthening neocortical connections (see Kandel, 2001, p. 1038).

MTT assumes, on the other hand, that the temporary MTL memory is fundamentally different from the permanent neocortical one. The former retains its episodic flavor, such that the semantic content is tied to the spatio-temporal (autobiographical) context in which it was acquired. The latter is stripped of its episodic context and retains only the semantic core (see illustrations in Figure 9). By this view, prolonged consolidation refers to the establishment of a semantic trace that can survive on its own, but it does not entail the loss of the episodic trace, nor is it identical to it (see McClelland, McNaughton, \& O'Reilly, 1995, for a computational model which argues for the necessity of two distinct memory systems and how the episodic contributes to the semantic, and Murre et al., 2001 for review of models of retrograde amnesia and semantic dementia ). Indeed, according to MTT, the two types of memories can co-exist, so that one can have both an episodic and a semantic representation of the same event, object, person, or fact, and that one can lose one kind of representation without losing the other (see Figure 10). These alternative interpretations make different predictions which we have tested both in humans and in nonhumans (see Rosenbaum, Winocur, \& Moscovitch, 2001). 

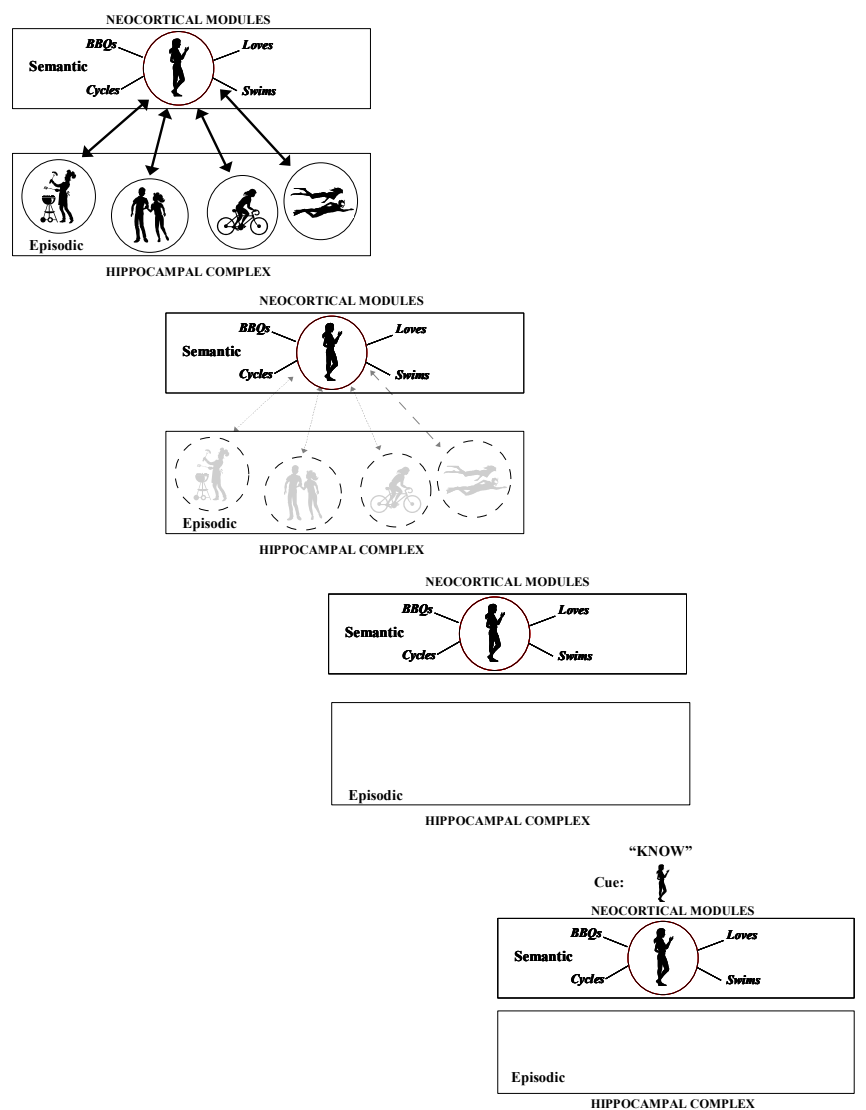

Fig. 9. The presumed, normal loss of episodic memory with time, with memories becoming increasingly semantic. The relation between hippocampus and neocortex in representing episodic and semantic memory during this process is also depicted. The top panel shows that shortly after engaging in an event with a person, such as swimming or cycling, autobiographical memories of the events are represented in the hippocampal complex with links to neocortex where semantic knowledge about the person, that she likes to cycle and swim, is also represented. With time, details of the autobiographical memories fade. In the end (bottom panel), what remains is only semantic knowledge about the person, represented in neocortex. Thus, one is left knowing many things about the person, but without having any autobiographical episodes associated with that knowledge. You only "know" that person but cannot "recollect" anything about her. 

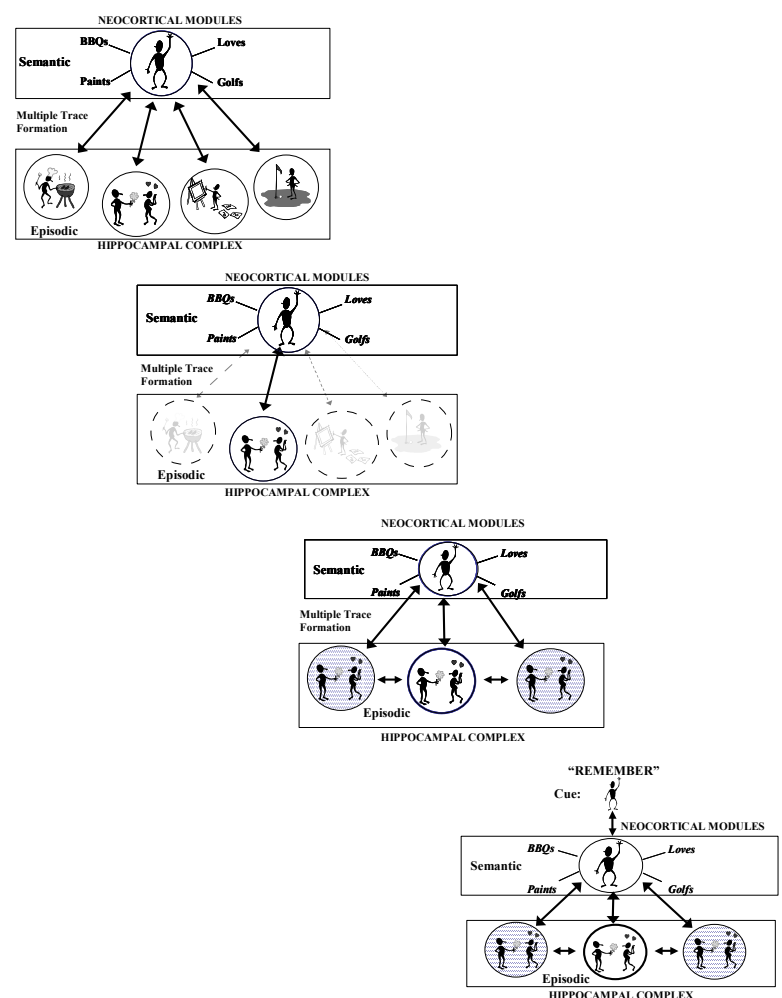

Fig. 10. The presumed, normal loss of episodic memory with time, with most memories becoming increasingly semantic, except that some autobiographical memories are preserved. The relation between hippocampus and neocortex in representing episodic and semantic memory during this process also is depicted. The top panel shows that shortly after engaging in an event with a person, such as swimming or cycling, autobiographical memories of the events are represented in the hippocampal complex with links to neocortex where semantic knowledge about the person, that he likes to golf and that he is romantic, is also represented. With time, details of most of autobiographical memories fade. The romantic encounter with the person, however, is recollected, and in doing so, is re-encoded as a memory, as described by MTT. As a result, there are multiple traces of that episode, each mediated by hippocampal-neocoritcal ensembles. In the end (bottom panel), one is left with many semantic memories associated with the person, which are represented in neocortex, but also with a few autobiographical memories of him. Thus, one not only "knows" many things about the person, but one can also "recollect" or "remember" some autobiographical episodes associated with him. 
The evidence from people with semantic dementia supports the MTT interpretation. People with SD read and recognize names of countries, cities, landmarks, people, and even common objects better if they have episodic or personally-significant memories associated with them (Graham et al., 1998; Snowden et al., 1994, 1996; Westmacott et al., 2001) than if they do not. Having lost semantic representation as a result of neocortical degeneration, people with SD rely on their relatively preserved MTL to represent these items within an autobiographical context. Put in other words, they recollect these names, events, and objects, rather than know them, in contrast to what the rest of us do. Conversely, amnesic people with medial temporal damage will recognize objects, words, and individuals regardless of their autobiographical significance, but will not be able to conjure an autobiographical event related to them (Westmacott et al., 2001).

MTT helps account for the different memory gradients in amnesia and semantic dementia. In semantic dementia, recent memories, both episodic and semantic, can be supported for a while by their relatively preserved MTL, perhaps by providing tonic input and support to degenerated neocortical neuronal ensembles. Alternatively, and more plausibly, their behavior suggests that, in the early stages of semantic memory acquisition, there is an episodic component to semantic knowledge that contributes to retention and retrieval. That is, the information is represented simultaneously by the hippocampal complex-neocortical ensemble as an episodic memory and by the neocortex as a semantic memory (see Figure 8 and Nadel \& Moscovitch, 1997, 1998; Nadel et al., 2003). Eventually, episodic support is no longer needed.

Unless they are rehearsed or revived, most hippocampally-dependent episodic memories fade within a relatively short time, leaving semantic memories primarily dependent on neocortex. Because their neocortex is degenerated, patients with SD cannot support remote semantic memories unless they are also represented in the hippocampal complex, as is the case for cities, countries, and landmarks which the patient remembers visiting. By contrast, amnesic patients with MTL damage cannot form new, elaborate semantic memories although they can gain some familiarity with new vocabulary and names of famous people (Corkin, 2002; Wesmacott et al., 2001; but see Kitchener et al., 1998; Van der Linden et al., 2001, for cases of well-preserved semantic memory acquisition). Older semantic memories, which were assimilated into the amnesic person's general knowledge, are retained well, and can be normal. 


\section{Test of the standard model's and MTT account of the pattern of semantic memory loss in amnesia and dementia}

To test the two models, Westmacott and I (Westmacott \& Moscovitch, 2003; Westmacott, Black et al., 2004) examined performance on two semantic memory tasks: fame judgment and speeded reading of names of famous people. According to traditional consolidation theory, both types of knowledge should be represented in neocortex if the names are not recent. MTT, other hand, predicts that insofar as the ostensibly semantic memory has autobiographical significance, that component of the memory is dependent on the hippocampal complex for both recent and remote names.

To obtain an independent measure of semantic and episodic components of name knowledge, we had a group of control participants make recollection (R) or familiarity or know (K) judgments to names. Westmacott and I were able to select 25 names which consistently were rated as R and another 25 which consistently were rated as $\mathrm{K}$, and which were matched for length, familiarity, and the amount of semantic knowledge participants had about them (see Figure 11).

Armed with these well-matched norms for a sample of names, we used them in our tests of fame judgment and speeded reading which we administered to a separate group of control participants who were not involved in collecting the norms. We found that reaction times (RTs) for fame judgments and speeded reading were significantly faster (by about $50 \mathrm{msec}$ ) for names with high $\mathrm{R}$ ratings as compared to those with low $\mathrm{R}$ (or $\mathrm{K}$ ) ratings. RTs to non-famous names were about $200 \mathrm{msec}$ slower (Westmacott \& Moscovitch, 2003) (see Figure 12 a, b).

If, as MTT predicts, the advantage of high $\mathrm{R}$ over low $\mathrm{R}$ names is dependent on the hippocampal complex, then the advantage should be diminished or absent in people with damage to those structures who have poor episodic memory, such as people with amnesia or with Alzheimer's disease. People with SD, on the other hand, should retain the high R advantage even though they have neocortical degeneration accompanied by semantic memory loss. If, however, high $\mathrm{R}$ responses to old names are neocortically-mediated, as the standard model predicts, then performance on high R names should not be selectively impaired in amnesia, but should be impaired in $\mathrm{AD}$ and $\mathrm{SD}$.

In accordance with MTT, but against the standard model, we found that the $\mathrm{R}$ advantage was lost in all four of the people with amnesia, and in all but one of over a dozen people with $\mathrm{AD}$ whom we tested (see Figure 11 a, b). By contrast, the two people with SD whom we tested showed a height- 


\section{NEOCORTICAL MODULES}

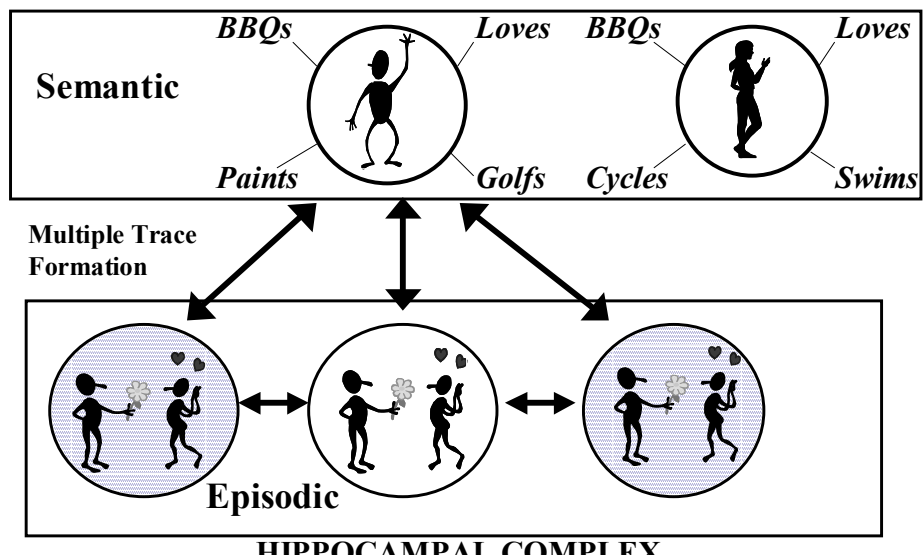

Fig. 11. The neural representations associated with people about whom one has both semantic and autobiographical memories (one both "knows" and "remembers" that person, see Figure 10), and about whom one has only semantic knowledge (one only "knows" that person, see Figure 9).

ened $\mathrm{R}$ advantage (see Figure $11 \mathrm{c}$ ). Thus, although tests of fame judgment and speeded reading are ostensibly semantic, our results show that they should more properly be considered tests of knowledge to which both semantic and episodic memory can contribute (Westmacott, Black, et al., 2004).

After completing the RT tests, we had our participants rate the names they had seen as R or K. In line with our findings on the RT test, we found that people with amnesia or Alzheimer's Disease gave R ratings to far fewer of the names than did the controls; in some cases, none of the names received an $\mathrm{R}$ rating. In contrast, the $\mathrm{SD}$ patients gave a larger than normal proportion of $\mathrm{R}$ ratings to names which they recognized (Westmacott, Black et al., 2004).

Taken together, these results favor the MTT interpretation of the preservation of remote semantic memory over the interpretation provided by the standard model. Remote semantic memories are different from their recent counterparts. Typically, they contain information only about the semantic core, without the context in which that information was acquired. This semantic knowledge is represented in extra-hippocampal structures. The autobiographical significance that may also be associated with that knowledge, on the other hand, is dependent on the hippocampus. When it is first 

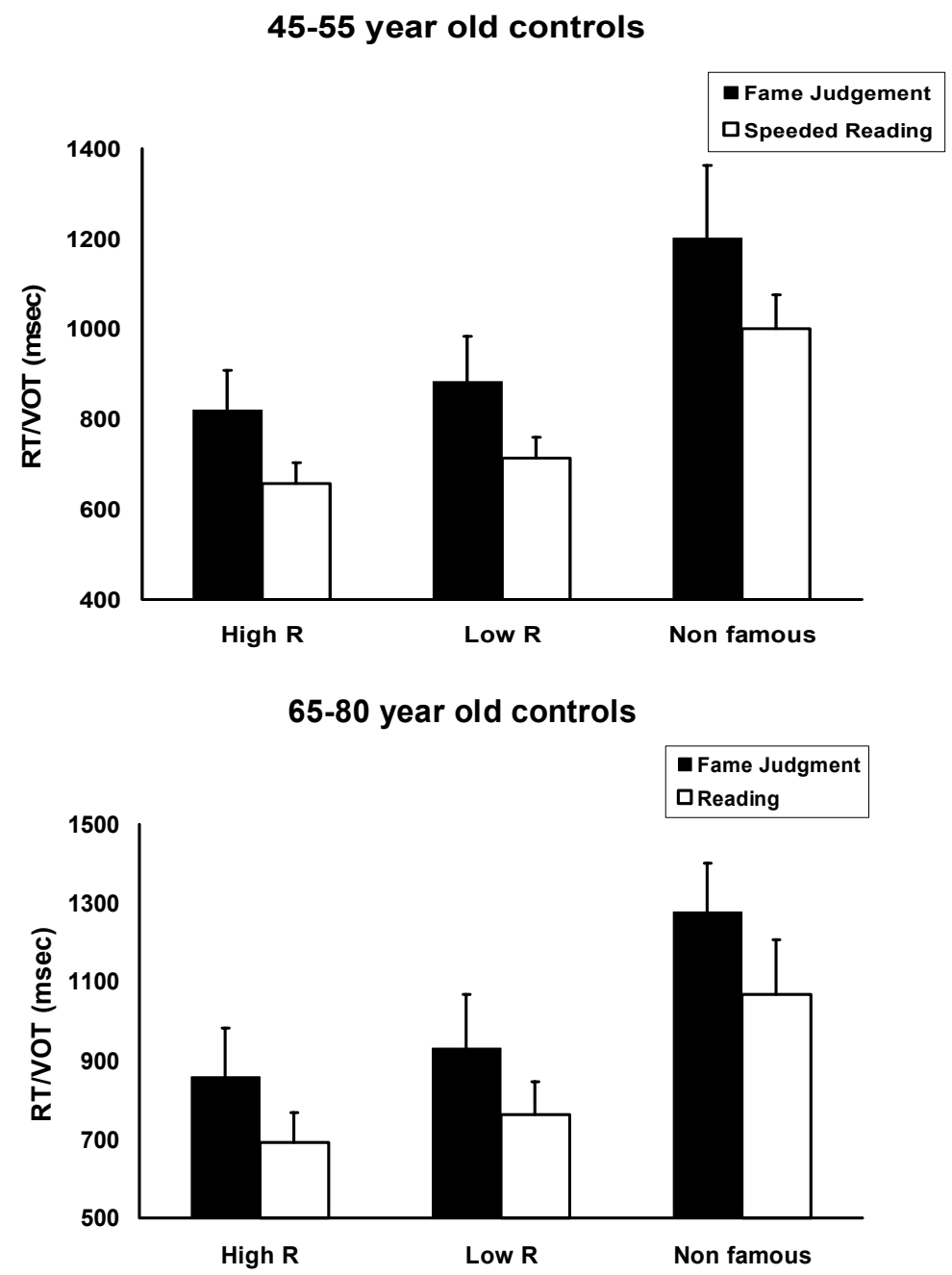

Fig. 12. Mean reaction times in msec (and standard error of the mean, SE) to make fame judgments, and voice onset times in msec (SE) to read names of famous or non-famous people. The famous names were rated as reliably eliciting recollection in the cohort (High R) or as unlikely to elicit recollection (Low R). Participants were healthy controls between 45-55 years old (top panel) or 65-80 years old (bottom panel). (From Westmacott \& Moscovitch, 2003). 


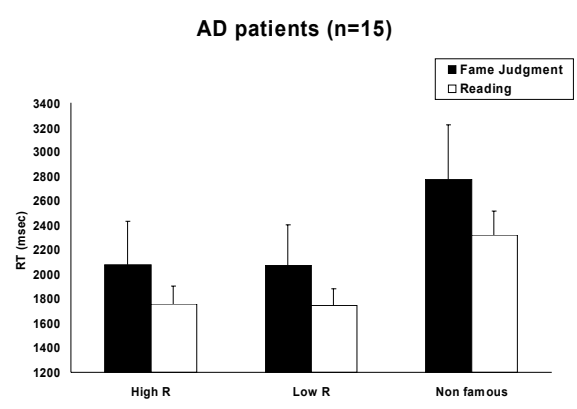

MTL Amnesic patients $(n=4)$
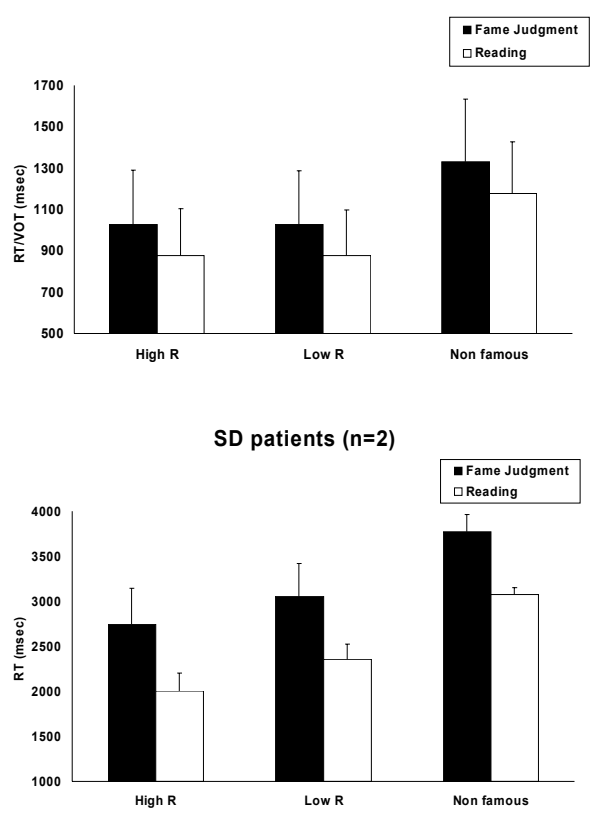

Fig. 13. Mean reaction times in msec (and standard error of the mean, SE) to make fame judgments, and voice onset times in msec (SE) to read names of famous or non-famous people. The famous names were rated as reliably eliciting recollection in the cohort (High R) or as unlikely to elicit recollection (Low R). Participants were patients diagnosed as having Alzheimer's Disease (AD) (top panel), patients with medial temporal lobe (MTL) lesions (middle panel), and patients diagnosed as having semantic dementia (SD; bottom panel). (From Westmacott, Black, et al., 2004). 
acquired, semantic knowledge often may be very highly associated with autobiographical context, and may need to be recovered via that route.

Summary. Unlike episodic memory, semantic memory for public events, people, vocabulary, and even facts about oneself (personal semantics) shows only a temporally-limited retrograde amnesia, lasting about ten years, in people with medial temporal/hippocampal lesions. Moreover, there are even cases showing that acquisition of semantic memory is possible after hippocampal lesions, although in most (but not all) cases learning is slow and the memory is not always elaborate. These findings are consistent with MTT and the standard model.

In comparison to the standard model, however, MTT argues that the "semantic" memory that benefits from hippocampal involvement during the initial period is not identical to the one that is retained after that initial vulnerable period has passed. What appears to be memory consolidation really is memory transformation, from a (semantic) memory embedded in a rich context to one in which the context has been lost, or become impoverished, so that only the semantic core remains. Evidence from humans (and rats, Rosenbaum et al, 2001) supports this idea, and also demonstrates that the two types of "semantic" memories can co-exist and contribute to performance in healthy people (and in rats).

\section{Conclusion}

The evidence reviewed suggests strongly that the function of the hippocampus (and possibly related limbic structures) is to help encode, retain, and retrieve experiences, no matter how long ago the events comprising the experiences occurred. Episodic or autobiographical memories are not comprised simply of the content of the event or the associations that make up the experience, but of the experience itself, insofar as that is possible. What this means is that some conscious awareness is bound up with that experience (in common parlance, that is what experience would implyhaving a non-conscious experience would simply be described as an event that happened to oneself but that one did not really experience).

This view of the function of the hippocampus borrows from Tulving's (1985) distinction between recollection and familiarity or knowing, and applies it to the component process model (Moscovitch, 1992, 1994, 1995, 2000; Moscovitch \& Umilta, 1990, 1991; Moscovitch \& Winocur, 1992, 2002) which states that the hippocampus is a structure that obligatorily encodes all information in conscious awareness. Via its connections with the neocortex and other structures, the hippocampus binds the elements of the 
experience, and the consciousness that accompanied it, into a memory trace.

The hippocampal component of the memory trace is a sparselydistributed code that acts as a pointer or index to the brain regions that represent elements of the experience (Teyler \& DiScenna, 1986). It is via that pointer or index that the memory trace is reactivated so that the event can be re-experienced. Thus, although the memory of the experience is dependent on the hippocampus, it does no reside there, but is distributed throughout those regions of the brain that represent the multifaceted elements of the experience and that are reactivated in concert by the hippocampus.

Emerging evidence from studies of recently-acquired memories in the laboratory suggests that it is recollection, i.e., memory of an experience, that is particularly dependent on the hippocampus. Developing MTT, Nadel and I (1997, 1998; Moscovitch \& Nadel, 1999; Moscovitch et al., 1999) proposed that the same applies to remote memories: Detailed memories of autobiographical episodes always depend on the hippocampus no matter how long ago they were formed. Contrary to the standard view, such memories are not consolidated elsewhere in the brain.

By contrast, semantic memories of public events, of people, of vocabulary, of facts about oneself (personal semantics), and even of the gist of events without their experiential component (familiarity without recollection), can be represented without the hippocampus, though it may benefit initially from hippocampal involvement. Memories which appear to be consolidated with time on closer inspection seem to be transformed from those which are experientially-based to those which are more semantic. The evidence that we have reviewed from lesions and neuroimaging studies is, for the most part, consistent with these proposals, though some issues remain to be resolved. MTT provides a parsimonious view of memory and hippocampal function across time, from anterograde to retrograde: As long as the memory is experiential, it will always depend on the hippocampus.

Making experience and re-experience the foundation of hippocampal memory opens many new problems. We do not know what it truly means to travel back in time and re-experience an event. Nothing is reexperienced as it had occurred. Memory is reconstructive, not reduplicative, of experience. Furthermore, as Gilboa (2004) noted, we do not have direct measures of what constitutes the experiential part of memory. Instead, we have to rely on close correlates, such as the number of details, and ratings of vividness and personal significance (Addis et al., 2004a; Gilboa et al, 2004; Levine et al, 2002; Moscovitch et al, 1999). Using judgments of recollection gets at the same thing. All of these, except actu- 
ally measuring the number of details one can remember, are subjective measures which carry problems of their own. Nonetheless, rather than revert to some objective measure which does not capture the essence of reexperiencing, new procedures can be developed that will allow us to investigate the implications of an experientially-based view of memory and hippocampal function in humans and other animals (see Rosenbaum et al., 2001; Eichenbaum, 2001; Fortin, Agster, \& Eichenbaum, 2002; Fortin, Wright, \& Eichenbaum 2004; Martin, de Hoz, \& Morris, in press; Winocur, 1990; Winocur, MacDonald and Moscovitch, 2001; Winocur, Moscovitch, Caruana, \& Binns, submitted).

\section{Author Notes}

This research was supported by Canadian grants from the Natural Science and Engineering Research Council, from the Canadian Institutes of Health Research, and Heart and Stroke Foundation of Canada, Saul A. Silverman Family Foundation, and by grants from the New Zealand Granting Council and the U.S. National Institute of Mental Health to the various co-authors.

We thank Endel Tulving, whose ideas about the nature of memory informed much of the theoretical and empirical work reported in this chapter and whose encouragement supported us against our critics. In particular, it was his ideas about the distinction between episodic and semantic memory, and the further distinction between "remembering" and "knowing," that allowed us to appreciate his observation of the loss of episodic memory in amnesia, and to place it all in a neuropsychological framework (see Rosenbaum et al., in press).

Correspondence may be sent to Morris Moscovitch by e-mail at momos@psych.utoronto.ca. The order of authorship for the senior scientists, beginning with Black and ending with Winocur, is alphabetical. We thank Nasim Radkhoshnoud for technical help.

\section{References}

Addis, D. R., Moscovitch, M., Crawley, A. P., \& McAndrews, M. P. (2004a). Recollective qualities modulate hippocampal activation during autobiographical memory retrieval. Hippocampus, 14, 752-762.

Addis, D. R., McIntosh, A. R., Moscovitch, M., Crawley, A. P., and McAndrews, M. P. (2004b). Characterising the spatial and temporal features of autobiographical memory retrieval networks: A partial least squares approach. NeuroImage, 23, 1460-1471. 
Aggleton, J. P., \& Brown M. W. (1999). Episodic memory, amnesia, and the hippocampal-anterior thalamic axis. Behavioral and Brain Sciences, 22, 425-489.

Aggleton, J. P., McMackin, D., Carpenter, K., Hornak, J., Kapur, N., Halpin, S., Wiles, C. M., Kamel, H., Brennan, P., Carton, S., \& Gaffan, D. (2000). Differential cognitive effects of colloid cysts in the third ventricle that spare or compromise the fornix. Brain, 123, 800-815.

Bayley, P. J., Hopkins, R. O., \& Squire, L. R. (2003). Successful recollection of remote autobiographical memories by amnesic patients with medial temporal lobe lesions. Neuron, 38, 135-144.

Burgess, N., Becker, S., King, J. A., \& O'Keefe, J. (2001). Memory for events and their spatial context: Models and experiments. Philosophical Transactions of the Royal Society of London, 356, 1493-1503.

Burgess, N., Maguire, E. A., \& O'Keefe, J. (2002). The human hippocampus and spatial and episodic memory. Neuron, 35, 625-641.

Burnham, W.H. (1904). Retroactive amnesia: Illustrative cases and a tentative explanation. American Journal of Psychology, 14, 382-396.

Caza, N., McAndrews, M. P., Hoque, T., Ziegler, M., Crawley, M., \& Moscovitch, M. (2004). Neural basis for remembering and knowing in associative memory. Paper presented at a conference on cognitive neuroscience, Montreal, July, 2004.

Cermak L. S. (Ed.) (1982). Human memory and amnesia. Hillsdale, NJ: Lawrence Erlbaum Associates,

Cermak, L.S. (1989). Synergistic ecphory and the amnesic patient. In H. L. Roediger III \& F. I. M. Craik (Eds.), Varieties of memory and consciousness: Essays in honour of Endel Tulving (pp. 121-132). Hillsdale, NJ: Lawrence Erlbaum Associates.

Cermak. L. S., \& O'Connor, M. (1983). The anterograde and retrograde retrieval ability of a patient with amnesia due to encephalitis. Neuropsychologia, 21, 213-34.

Cipilotti, L., Shallice, T., Chan, D., Fox, N., Scahill, R., Harrison, G., Stevens, J., \& Rudge, P. (2001). Long-term retrograde amnesia: The crucial role of the hippocampus. Neuropsychologia, 39, 151-172.

Conway, M. A., \& Fthenaki, A. K. (2000). Disruption and loss of autobiographical memory. In L. S. Cermak (Ed.), Handbook of neuropsychology: Memory (pp. 257-288). Amsterdam: Elsevier.

Conway, M. A., \& Pleydell-Pearce, C. W. (2000). The construction of autobiographical memories in the self-memory system. Psychological Review, 107, 261-288.

Conway, M. A., Turk, D. J., Miller, S. L., Logan, J., Nebes, R. D., Meltzer, C. C., \& Becker, J. T. (1999). A positron emission tomography (PET) study of autobiographical memory retrieval. Memory, 5-6, 679-702.

Corkin, S. (1984). Lasting consequences of bilateral medial temporal lobectomy: Clinical course and experimental findings in H.M. Seminars in Neurology, 4, 252-262.

Corkin, S. (2002). What's new with the amnesic patient H.M.? Nature Reviews: Neuroscience, 3, 153-160. 
Corkin, S., Amaral, D. G., Gonzalez, G., Johnson, K. A., \& Hyman, B. T. (1997). H.M.'s medial temporal lobe lesion: Findings from magnetic resonance imaging. Journal of Neuroscience, 17, 3964-3979.

Crovitz, H. F., \& Schiffman, H. (1974). Frequency of episodic memories as a function of their age. Bulletin of the Psychonomic Society, 4, 519-521.

Davachi, L., Mitchell, J. P., Wagner, A. D. (2003). Multiple routes to memory: Distinct medial temporal lobe processes build item and source memories. Proceedings of the National Academy of Sciences, USA, 100, 2157-2162.

Dolcos, F., LaBar, K. S., \& Cabeza, R. (2002). Interaction between the amygdala and the medial temporal lobe memory system predicts better memory for emotional events. Neuron, 42, 855-863.

Dudai, Y. (2004). The neurobiology of consolidations, or, how stable is the engram? Annual Review of Psychology, 55, 51-86.

Eichenbaum, H. (2001). The hippocampus and declarative memory: Cognitive mechanisms and neural codes. Behavioral Brain Research, 127, 199-207.

Eldridge, L. L., Knowlton, B. J., Furmanski, C. S., Bookheimer, S. Y., \& Engel, S. A. (2000). Remembering episodes: A selective role for the hippocampus during retrieval. Nature Neuroscience, 3, 1149-1152.

Epstein, R., Graham, K. S., \& Downing, P. E. (2003). Viewpoint-specific scene representations in human parahippocampal cortex. Neuron, 37, 865-876.

Epstein, R., Harris, A., Stanley, D., \& Kanwisher, N. (1999). The parahippocampal place area: Recognition, navigation, or encoding? Neuron, 23, 115-125.

Epstein, R., \& Kanwisher, N. (1998). A cortical representation of the local visual environment. Nature, 392, 598-601.

Estes, W.K. (1964). All or none processes in learning and retention. American Psychologist, 19, 16-25.

Eustache, F., Piolino, P., Giffard, B., Viader, F., De La Sayette, V., Baron, J.-C., \& Desgranges, B. (2003). "In the course of time": A PET study of the cerebral substrates of autobiographical amnesia in Alzheimer's disease. Brain, 127, 1549-1560.

Fortin, N. J., Agster, K. L., \& Eichenbaum, H. (2002). Critical role of the hippocampus in memory for sequences of events. Nature Neuroscience, 5, 458462.

Fortin, N.J., Wright, S.P., \& Eichenbaum, H. (2004). Recollection-like memory retrieval in rats is dependent on the hippocampus. Nature, 431, 188-191.

Frankland, P. W., \& Bontempi, B. (in press). The organization of recent and remote memories. Nature Reviews: Neuroscience.

Fujii, T., Moscovitch, M., \& Nadel, L. ( 2000). Consolidation, retrograde amnesia, and the temporal lobe. In F. Boller and J. Grafman (Eds.), The Handbook of Neuropsychology, $2^{\text {nd }}$ edition, Vol. 4 (L. S. Cermak, section ed., pp. 223-250). Amsterdam: Elsevier.

Gadian, D.G., Aicardi, J., Watkins, K.E., Porter, D.A., Mishkin, M., \& VarghaKhadem, F. (2000) Developmental amnesia associated with early hypoxicischaemic injury. Brain, 123, 499-507. 
Galef, B. G., Jr., \& Wigmore, S. R. (1983). Transfer of information concerning distant foods: A laboratory investigation of the 'information-centre' hypothesis. Animal Behavior, 31, 748-758.

Gilboa, A. (2004). Neuropsychology of remote and recent autobiographical memory. Unpublished doctoral thesis, University of Toronto.

Gilboa, A., Ramirez, J., Köhler, S., Westmacott, R., Black, S. E., \& Moscovitch, M. (submitted). Retrieval of autobiographical memory in Alzheimer's disease: Relation to volumes of medial temporal lobe and other structures.

Gilboa, A., Winocur, G., Grady, C. L., Hevenor, S. J., \& Moscovitch, M. (2004). Remembering our past: Functional neuroanatomy of recollection of recent and very remote personal events. Cerebral Cortex, in press.

Graf, P., \& Schacter, D. L. (1985). Implicit and explicit memory for new associations in normal and amnesic subjects. Journal of Experimental Psychology: Learning, Memory, \& Cognition. 11, 501-518.

Graham, K. S., \& Hodges, J. R. (1997). Differentiating the roles of the hippocampal system and the neocortex in long-term memory storage. Neuropsychology, $11,77-89$.

Graham, K. S., Patterson, K., \& Hodges, J. R. (1999). Episodic memory: New insights from the study of semantic dementia. Current Opinion in Neurobiology, 9, 245-250.

Graham, K. S., Lee, A. C. H., Brett, M., \& Patterson, K. (2003). The neural basis of autobiographical and semantic memory: New evidence from three PET studies. Cognitive, Affective, \& Behavioral Neuroscience, 3, 234-254.

Greenberg, D. L., \& Rubin, D. C. (2003). The neuropsychology of autobiographical memory. Cortex, 39, 687-728.

Haist, F., Bowden Gore, J., \& Mao, H. (2001). Consolidation of human memory over decades revealed by functional magnetic resonance imaging. Nature Neuroscience, 4, 1139-1145.

Holdstock, J. S., Mayes, A. R., Roberts, N., Cezayirli, E., Isaac, C. L., O’Reilly, R. C., \& Norman, K. A. (2002a). Under what conditions is recognition spared relative to recall after selective hippocampal damage? Hippocampus, 12, 341-351.

Holdstock, J. S., Mayes, A. R., Isaac, C. L., \& Roberts, J. N. (2002b). Differential involvement of the hippocampus and temporal cortices in rapid and slow learning of new semantic information. Neuropsychologia, 40, 748-768.

Ivanoiu, A., Cooper, J. M., Shanks, J. M., \& Venneri, A. (2004). Retrieval of episodic and semantic autobiographical memories in early Alzheimer's Disease and semantic dementia. Cortex, 40, 173-175.

Kandel, E. R. (2001). The molecular biology of memory storage: A dialogue between genes and synapses. Science, 294, 1030-1038.

Kapur, N. (1999). Syndromes of retrograde amnesia: A conceptual and empirical analysis. Psychological Bulletin, 125, 800-825.

Kim, J. J., \& Fanselow, M. S. (1992). Modality-specific retrograde amnesia of fear. Science, 256, 675-667. 
Kinsbourne, M., \& Wood, F. (1975). Short-term memory processes and the amnesic syndrome. In D. Deutsch and A. J. Deutsch (Eds.), Short-term memory (pp. 258-291). New York: Academic Press.

Kitchener, E. G., Hodges, J. R., \& McCarthy, R. (1998). Acquisition of postmorbid vocabulary and semantic facts in the absence of episodic memory. Brain, 121, 1313-1327.

Kitchener, E. G., \& Hodges, J. R. (1999). Impaired knowledge of famous people and events and intact autobiographical knowledge in a case of progressive right temporal lobe degeneration: Implications for the organization of remote memory. Cognitive Neuropsychology, 16, 589-607.

Kitchener, E. G., Squire, L. R. (2000). Impaired verbal category learning in amnesia. Behavioral Neuroscience, 114, 907-911.

Kopelman, M. D., \& Kapur, N. (2001). The loss of episodic memories in retrograde amnesia: Single-case and group studies. Philosophical Transactions of the Royal Society of London, Series B: Biological Sciences, 356, 1409-1421.

Kopelman, M. D., Stanhope, N., \& Kingsley, D. (1999). Retrograde amnesia in patients with diencephalic, temporal lobe or frontal lesions. Neuropsychologia, 37, 939-958.

Kopelman, M. D., Wilson, B. A., \& Baddeley, A. D. (1989). The autobiographical memory interview: A new assessment of autobiographical and personal semantic memory in amnesic patients. Journal of Clinical and Experimental Neuropsychology, 5, 724-744.

Kopelman, M. D, Lasserson, D., Kingsley, D. R., Bello, F., Rush, C., Stanhope, N., et al. (2003). Retrograde amnesia and the volume of critical brain structures. Hippocampus, 13, 879-891.

Korsakoff, S. S. (1889). Etudes medico psychologique sur une forme du maladi de la memoire. Revue Philosophique, 28, $501-530$ (Translated and republished by M. Victor and P. I. Yakovlev (1955). Neurology, 5, 394-406).

Leveroni, C. L., Seidenberg, M., Mayer, A. R., Mead, L. A., Binder, J. R., \& Rao, S. M. (2000). Neural systems underlying the recognition of familiar and newly learned faces. Journal of Neuroscience, 20, 878-886.

Levine, B., Svoboda, E., Hay, J. F., Winocur, G., \& Moscovitch, M. (2002). Aging and autobiographical memory: Dissociating episodic from semantic retrieval. Psychology and Aging, 17, 677-689.

Maguire, E. A. (2001). Neuroimaging studies of autobiographical event memory. Philosophical Transactions of the Royal Society of London: Biological Sciences, B, 356, 1441-1451.

Maguire, E. A., \& Frith, C. D. (2003). Lateral asymmetry in the hippocampal response to the remoteness of autobiographical memories. Journal of Neuroscience, 23, 5302-5307.

Maguire, E. A., Vargha-Khadem, F., \& Mishkin, M. (2001). The effects of bilateral hippocampal damage on fMRI regional activations and interactions during memory retrieval. Brain, 124, 1156-1170.

Manns, J. R., Hopkins, R. O., \& Squire, L. R. (2003). Semantic memory and the human hippocampus. Neuron 38, 127-133. 
Markowitsch, H. J. (1995). Which brain regions are critically involved in the retrieval of old episodic memory? Brain Research Reviews, 21, 117-127.

Martin, S. J., de Hoz, L., \& Morris, R. G. (in press). Retrograde amnesia: Neither partial nor complete hippocampal lesions in rats result in preferential sparing of remote spatial memory, even after reminding. Neuropsychologia

Mayes, A. R., Isaac, C. L., Holdstock, J. S., Cariga, P., Gummer, A., \& Roberts, N. (2003). Long-term amnesia: A review and detailed illustrative case study. Cortex, 39, 567-603.

Mayes, A. R., Holdstock, J. S., Isaac, C. L., Montaldi, D., Grigor, J., Gummer, A., Cariga, P., Downes, J. J., Tsivilis, D., Gaffan, D., Gong, Q., \& Norman, K. A. (2004). Associative recognition in a patient with selective hippocampal lesions and relatively normal item recognition. Hippoccampus, 14, 763-784.

McClelland, J. L., McNaughton, B. L., \& O'Reilly, R. C. (1995). Why there are complementary learning systems in the hippocampus and neocortex: Insights from the successes and failures of connectionist models of learning and memory. Psychological Review, 102, 419-457.

McGaugh, J. L. (2000). Memory - a century of consolidation. Science, 287, 248251.

Milner, B. (1966). Amnesia following operation on the temporal lobe. In C. W. M. Whitty and O. L. Zangwill (Eds.), Amnesia. (pp. 109-133). London: Butterworth.

Milner, B., Squire, L. R., \& Kandel, E. R. (1998). Cognitive neuroscience and the study of memory. Neuron, 20, 445-468.

Milner, P. M. (1989). A cell assembly theory of hippocampal amnesia. Neuropsychologia, 27, 23-30.

Moscovitch, D. A., \& McAndrews, M. P. (2002). Material-specific deficits in "remembering" in patients with unilateral temporal lobe epilepsy and excisions. Neuropsychologia, 40, 1335-1342.

Moscovitch, M. (1982). Multiple dissociation of function in the amnesic syndrome. In L. S. Cermak (Ed.), Human memory and amnesia (pp. 337-370). Hillsdale, NJ: Lawrence Erlbaum Associates.

Moscovitch, M. (1984). Spared and impaired memory functions in old people and in patients with memory disorders. In N. Butters \& L. R. Squire (Eds.), The neuropsychology of memory (pp. 104-114). New York: Guilford Press.

Moscovitch, M. (1992). Memory and working with memory: A component process model based on modules and central systems. Journal of Cognitive Neuroscience, 4, 257-267.

Moscovitch, M. (1994). Memory and working with memory: Evaluation of a component process model and comparisons with other models. In D.L. Schacter \& E. Tulving (Eds.), Memory systems 1994 (pp. 269-310). Cambridge, MA: MIT/Bradford Press.

Moscovitch, M. (1995). Recovered consciousness: A hypothesis concerning modularity and episodic memory. Journal of Clinical and Experimental Neuropsychology, 17, 276-291. 
Moscovitch, M. (2000). Theories of memory and consciousness. In E. Tulving \& F. I. M. Craik (Eds.), The Oxford handbook of memory (pp. 609-625). Oxford: Oxford University Press.

Moscovitch, M. (2001). Memory consolidation. In L. Nadel (Ed.), Encyclopedia of cognitive science. New York: Nature Publishing Group.

Moscovitch, M., \& Nadel, L. (1998). Consolidation and the hippocampal complex revisited: In defense of the multiple-trace model. Current Opinion in Neurobiology, 8, 297-300.

Moscovitch, M., Petrican, R., \& Gopie, N. (in preparation). Recollection and familiarity for public events in healthy young and older adults, and in memoryimpaired people.

Moscovitch, M., \& Umiltà, C. (1990). Modularity and neuropsychology: Modules and central processes in attention and memory. In M. F. Schwartz (Ed.), Modular deficits in Alzheimer's Disease (pp. 1-59). Cambridge, MA: MIT Press/Bradford.

Moscovitch, M., \& Umiltà, C. (1991). Conscious and nonconscious aspects of memory: A neuropsychological framework of modular and central systems. In R.G. Lister and H. J. Weingartner (Eds.), Prospectives in cognitive neuroscience (pp. 229-266). New York: Oxford University Press.

Moscovitch, M., Vriezen, E., \& Goshen-Gottstein, Y. (1993). Implicit tests of memory in patients with focal lesions or degenerative brain disorders. In F. Boller and H. Spinnler (Eds.), The Handbook of neuropsychology, Vol. 8 (pp. 133-173). Amsterdam: Elsevier.

Moscovitch, M., \& Winocur, G. (1992). The neuropsychology of memory and aging. In F. I. M. Craik \& T. A. Salthouse (Eds.), The handbook of aging and cognition (pp. 315-372). Hillsdale, NJ: Lawrence Erlbaum Associates.

Moscovitch, M., \& Winocur, G. (2002). The frontal cortex and working with memory. In D.T.Stuss \& R.T. Knight (Eds.), The frontal lobes (pp. 188-209). Oxford: Oxford University Press.

Moscovitch, M., Yaschyshyn, T., Ziegler, M., \& Nadel, L. (1999). Remote episodic memory and amnesia: Was Endel Tulving right all along? In E. Tulving ( Ed.), Memory, consciousness and the brain: The Tallinn conference (pp. 331-345). New York: The Psychology Press.

Moss, H. E., Kopelman, M. D., Cappelletti, M., de Mornay Davies, P., \& Jaldow, E. (2003). Lost for words or loss of memories? Autobiographical memory in semantic dementia. Cognitive Neuropsychology, 20, 703-732.

Müller, G. E., \& Pilzecker, A. (1900). Experimentelle beiträge zur lehre vom gedächtnis. Zeitschrift für Psychologie und Physiologie der Sinnesorgane. S1, 1-288 (summarized by W. McDougall, Critical Notives, American Journal of Psychology, 388-394.)

Mummery, C. J., Patterson, K., Price, C. J., Ashburner, J., Frackowiak, R. S. J., \& Hodges, J. R. (2000). A voxel-based morphometry study of semantic dementia: Relationship between temporal lobe atrophy and semantic dementia. Annals of Neurology, 47, 36-45.

Murray, E. A., \& Bussey, T. J. (2001). Consolidation and the medial temporal lobe revisited: Methodological considerations. Hippocampus, 11, 1-7. 
Murray, E. A., \& Richmond, B. J. (2001). Role of perirhinal cortex in object perception, memory, and associations. Current Opinion in Neurobiology, 11,188193.

Murre, J. M. J., Graham, K. S., \& Hodges, J. R. (2001). Semantic dementia: Relevance to connectionist models of long term memory. Brain, 124, 647675 .

Nadel, L., \& Moscovitch, M. (1997). Memory consolidation, retrograde amnesia and the hippocampal complex. Current Opinion in Neurobiology, 7, 217-227.

Nadel, L., \& Moscovitch, M. (1998). Hippocampal contributions to cortical plasticity. Neuropharmacology, 37, 431-439.

Nadel, L., \& Moscovitch, M. (2001). The hippocampal complex and long-term memory revisited. Trends in Cognitive Neuroscience, 5, 228-230.

Nadel, L., Ryan, L., Hayes, S. M., Gilboa, A., \& Moscovitch, M. (2003). The role of the hippocampal complex in long-term episodic memory. In T. Ono, G. Matsumoto, R. R. Lllinas, A. Berthoz, R. Norgen, H. Nishijo, \& R. Tamura (Eds.), Limbic and association cortical systems - basic, clinical and computational aspects. Amsterdam: Elsevier Science/Excerpta Medica International Congress Series).

Nadel, L., Samsonovich, A., Ryan, L., \& Moscovitch, M. (2000). Multiple trace theory of human memory: Computational, neuroimaging, and neuropsychological results. Hippocampus, 10, 352-368.

Nestor, P. J., Graham, K. S., Bozeat, S., Simons, J. S., \& Hodges, J. R. (2002). Memory consolidation and the hippocampus: Further evidence from the study of autobiographical memory in semantic dementia and the frontal variant of frontotemporal dementia. Neuropsychologia, 40, 633-654.

Niki, K., \& Luo, J. (2002). An fMRI study on the time-limited role of the medial temporal lobe in long-term topographical autobiographic memory. Journal of Cognitive Neuroscience, 14, 500-507.

O'Kane, G., Kensinger, E. A., \& Corkin, S. (2004). Evidence for semantic learning in profound amnesia: An investigation with patient H.M. Hippocampus, 14, 417-25.

O'Keefe, J., \& Nadel, L. (1978). The hippocampus as a cognitive map. Oxford: Oxford University Press

Ogden, J. A. (1993). Visual object agnosia, prosopagnosia, achromatopsia, loss of visual imagery, and autobiographical amnesia following recovery from cortical blindness: Case M.H. Neuropsychologia, 31, 571-589.

Owen, A. M., Milner, B., Petrides, M., \& Evans, A. C. (1996a). Memory for object features versus memory for object location: A positron-emission tomography study of encoding and retrieval processes. Proceedings of the $\mathrm{Na}$ tional Academy of Sciences, USA, 93, 9212-9217.

Owen, A. M., Milner, B., Petrides, M., \& Evans, A. C. (1996b). A specific role for the right parahippocampal gyrus in the retrieval of object-location: A positron emission tomography study. Journal of Cognitive Neuroscience, 8, 588- 602.

Penfield, W., \& Milner, B. (1957). Memory deficit produced by bilateral lesions in the hippocampal zone. Archives of Neurology and Psychiatry, 79, 475-497. 
Piefke, M., Weiss, P. H., Zilles, K., Markowitsch, H. J., \& Fink, G.R. (2003). Differential remoteness and emotional tone modulate the neural correlates of autobiographical memory. Brain, 126, 650-668.

Piolino, P., Desgranges, B., Belliard, S., Matuszewski, V., Lalevee, C., De la Sayette, V., \& Eustache, F. (2003). Autobiographical memory and autonoetic consciousness: Triple dissociation in neurodegenerative diseases. Brain, 126, 2203-2219.

Piolino, P., Giffard-Quillon, G., Desgranges, B., Che'telat, G., Baron, J.-C., \& Eustache, F. (2004). Re-experiencing old memories via hippocampus: A PET study of autobiographical memory. Neurolmage, 22, 1371-1383.

Reed, J. M., \& Squire, L. R.(1998). Retrograde amnesia for facts and events: Findings from four new cases. Journal of Neuroscience, 18, 3943-3954.

Rempel-Clower, N. L., Zola, S. M., Squire, L. R., \& Amaral D. G. (1996). Three cases of enduring memory impairment after bilateral damage limited to the hippocampal formation. Journal of Neuroscience, 16, 5233-5255.

Rosenbaum, R. S., Priselac, S., Köhler, S., Black, S. E., Gao, F., Nadel, L., \& Moscovitch, M. (2000). Remote spatial memory in an amnesic person with extensive bilateral hippocampal lesions. Nature Neuroscience, 3, 1044-1048.

Rosenbaum, R. S., Winocur, G., \& Moscovitch, M. (2001). New views on old memories: Re-evaluating the role of the hippocampal complex. Behavioral Brain Research, 127,183-197.

Rosenbaum, R. S., Kohler, S., Schacter, D. L., Black, S., Gao, X., Moscovitch, M., \& Tulving, E. (in press). The Case of KC: Contributions of a memoryimpaired person to memory theory. Neuropsychologia.

Rubin, D. C., \& Greenberg, D. L. (1998). Visual memory deficit amnesia: A distinct amnesic presentation and etiology. Proceedings of the national Academy of Sciences, USA, 95, 5413-5416.

Ryan, L., Nadel, L., Keil, K., Putnam, K., Schnyer, D., Trouard, T., \& Moscovitch, M. (2001). Hippocampal complex and retrieval of recent and very remote autobiographical memories: Evidence from functional magnetic resonance imaging in neurologically intact people. Hippocampus, 11, 707-714.

Schacter, D.L. (1987). Implicit memory: History and current status. Journal of Experimental Psychology: Learning, Memory, and Cognition, 13, 501-518.

Schacter, D. L., \& Tulving, E. (Eds.) (1994). Memory Systems 1994. Cambridge, MA: MIT/Bradford Press.

Scoville, W. B., \& Milner, B. (1957). Loss of recent memory after bilateral hippocampal lesions. Journal of Neurology, Neurosurgery and Psychiatry, 20, 1121.

Seidenberg, M., Hermann, B.P., Schoenfeld, J., Davies, K., Wyler, A. \& Dohan, F.C. (1997) Reorganization of verbal memory function in early onset left temporal lobe epilepsy. Brain and Cognition, 35, 132-148.

Shimamura, A. P. (2002). Relational between binding theory and the role of consolidation in memory retrieval. In L. R. Squire \& D. L. Schacter (Eds.), Neuropsychology of memory, $3^{\text {rd }}$ ed (pp. 61-72). New York: Guilford Press. 
Skotko, B., Kensinger, E. A., Locascio, J. J., Einstein, J. G., Ruin, D. C., Tupler, L. A., et al. (in press). Can new semantic memories be anchored to old semantic memories? Neuropsychology.

Snowden, J. S., Griffiths, H. L., \& Neary, D. (1994). Semantic dementia: Autobiographical contribution to preservation of meaning. Cognitive Neuropsychology, 11, 265-288.

Snowden, J. S., Griffiths, H. L., \& Neary, D. (1996). Semantic-episodic memory interactions in semantic dementia: Implications for retrograde memory function. Cognitive Neuropsychology, 13, 1101-1137.

Squire, L. R. (1992). Memory and the hippocampus: A synthesis from findings with rats, monkeys and humans. Psychological Review, 99, 195-231.

Squire, L. R., \& Alvarez, P. (1995). Retrograde amnesia and memory consolidation: A neurobiological perspective. Current Opinion in Neurobiology, 5, 169-177.

Squire, L. R., Cohen, N. J., \& Nadel, L. (1984). The medial temporal region and memory consolidation: A new hypothesis. In H. Weingartner and E. Parker (Eds), Memory consolidation (pp. 185-210). Hillsdale, NJ: Lawrence Erlbaum Associates.

Squire, L. R., \& Zola, S. M. (1998). Episodic memory, semantic memory, and amnesia. Hippocampus, 8, 205-211.

Talairach, J., \& Tournoux, P. (1988). Co-planar stereotaxic atlas of the human brain. New York: Thieme Medical Publishers.

Teyler, T. J., \& DiScenna, P. (1986). The hippocampal memory indexing theory. Behavioral Neuroscience, 100, 147-154.

Tranel, D., Damasio, H., \& Damasio, A. R. (1997). A neural basis for the retrieval of conceptual knowledge. Neuropsychologia, 35,1319-1327.

Tulving, E. (1972). Episodic and semantic memory. In E. Tulving and W. Donaldson (Eds.), Organization of memory (pp. 381-403). New York: Academic Press.

Tulving, E. (1983). Elements of episodic memory. Oxford, UK: Clarendon Press.

Tulving, E. (1985). Memory and consciousness. Canadian Psychologist, 25, 1-12.

Tulving, E., \& Craik, F. I. M. (Eds.) (2000). The Oxford handbook of memory. Oxford: Oxford University Press,

Van der Linden, M., Cornil, V., Meulemans, T., Ivanoiu, A., Salmon, F., \& Coyette, F. (2001) Acquisition of a novel vocabulary in an amnesic patient. Neurocase, 7, 283-293.

Vargha-Khadem, F., Gadian, D. G., Watkins, K. E., Conneley, A., Van Paesschen, W., \& Mishkin M. (1997). Differential effects of early hippocampal pathology on episodic and semantic memory. Science, 277, 376-380.

Viskontas, I. V., McAndrews, M. P., \& Moscovtich, M. (2000). Remote episodic memory deficits in patients with unilateral temporal lobe epilepsy and excisions. Journal of Neuroscience, 20, 5853-5857.

Warrington, E. K. (1996). Studies of retrograde memory: A long-term view. Proceedings of the National Academy of Sciences, 93, 13523-13526.

Warrington, E. K., \& McCarthy, R. A. (1988). The fractionation of retrograde amnesia. Brain and Cognition, 7, 184-200. 
Warrington, E. K., \& Sanders, H. I. (1971). The fate of old memories. Quarterly Journal of Experimental Psychology, 23, 432-442.

Warrington, E. K., \& Weiskrantz, L. (1970). Amnesic syndrome: Consolidation or retrieval? Nature, 228, 628-630.

Westmacott, R., Black, S. E., Freedman, M., \& Moscovitch, M. (2004). The contribution of autobiographical significance to semantic memory: Evidence from Alzheimer's disease, semantic dementia, and amnesia. Neuropsychologia, 42, 25-48.

Westmacott, R., Freedman, M., Black, S. E., Stokes, K. A., \& Moscovitch, M. (2004). Temporally graded semantic memory loss in Alzheimer's Disease: Cross-sectional and longitudinal studies. Cognitive Neuropsychology, 21, 353378.

Westmacott R., Leach, L., Freedman, M., \& Moscovitch, M. (2001). Different patterns of autobiographical memory loss in semantic dementia and medial temporal lobe amnesia: A challenge to consolidation theory. Neurocase, 7, 37-55.

Westmacott, R., \& Moscovitch, M. (2001). Names and words without meaning: Incidental post-morbid semantic learning in a person with extensive bilateral medial temporal lobe damage. Neuropsychology, 15, 586-596.

Westmacott, R., \& Moscovitch, M. (2002). Temporally graded semantic memory loss in amnesia and semantic dementia: Further evidence for opposite gradients. Cognitive Neuropsychology, 19, 135-163.

Westmacott, R., \& Moscovitch, M. (2003). The contribution of autobiographical significance to semantic memory. Memory \& Cognition, 31, 761-774.

Wechsler, D. B. (1963). Engrams, memory storage, and mnemonic coding. American Psychologist, 18, 149-153.

Winocur, G. (1990). Anterograde and retrograde amnesia in rats with dorsal hippocampal or dorsomedial thalamic lesions. Behavioral Brain Research, 38, $145-154$

Winocur, G., McDonald, R. M., \& Moscovitch, M. (2001). Anterograde and retrograde amnesia in rats with large hippocampal lesions. Hippocampus, 11,1826.

Winocur, G., Moscovitch, M., Caruana, D.A. \& Binns, M.A. (submitted). Retrograde amnesia in rats with lesions to the hippocampus on a test of spatial memory.

Yonelinas, A. P. (2002). The nature of recollection and familiarity: A review of 30 years of research. Journal of Memory and Language, 46, 441-517.

Yonelinas, A. P., Kroll, N. E. A., Quamme, J. R., Lazzara, M. M., Sauve, M.-J., Widaman, K. F., \& Knight, R. T. (2002). Effects of extensive temporal lobe damage or mild hypoxia on recollection and familiarity. Nature Neuroscience, 5, 1236-1241.

Zola-Morgan, S., \& Squire, L. R. (1990). The primate hippocampal formation: Evidence for a time-limited role in memory storage. Science, 250, 288-290. 